\title{
Crescimento econômico em economias emergentes selecionadas: Brasil, Rússia, Índia, China (BRIC) e Âfrica do Sul ${ }^{1}$
}

\author{
Flávio Vilela Vieira ${ }^{2}$ \\ Michele Polline Veríssimo ${ }^{3}$
}

\section{Resumo}

$\mathrm{O}$ artigo investiga, do ponto de vista teórico e empírico, os principais determinantes das taxas de crescimento econômico para Brasil, Rússia, Índia, China (BRIC) e África do Sul. Os resultados empíricos da análise de decomposição de variância (ADV) para o crescimento do PIB real revelaram uma predominância do papel da taxa de investimento e da inflação para o crescimento econômico desses países, ainda que outros fatores, como a taxa de juros real (Brasil, Índia e África do Sul), a taxa de câmbio real efetiva (China e Índia), os fluxos de IDE (China e África do Sul) e o crescimento populacional (Índia e Rússia) tenham sido importantes, embora com uma contribuição menor em termos relativos.

Palavras-chave: Desenvolvimento econômico; Brasil - Relações econômicas internacionais; Economias emergentes; BRICs.

\section{Abstract \\ Economic growth in selected emerging economies: Brazil, Russia, India, China (BRIC) and South Africa}

The paper investigates on theoretical and empirical grounds the main determinants of economic growth for Brazil, Russia, India, China (BRIC) and South Africa. The empirical results from the variance decomposition analysis (VDA) for the real GDP growth reveal a primary role played by the investment rate and inflation to explain economic growth in these countries, but other factors, such as the real interest rate (Brazil, India and South Africa), the real effective exchange rate (China and India), FDI flows (China and South Africa) and population growth (India and Russia) are also important, regardless of their lower relative contribution.

Key words: Economic development; Foreign economic policy; Emerging economies; BRICs. JEL O11, C32, 057.

\section{Introdução}

Estudos recentes indicam que o conjunto de países emergentes formado por Brasil, Rússia, Índia, China (BRIC) e África do Sul poderá se tornar, nos

(1) Trabalho recebido em setembro de 2007 e aprovado em julho de 2008.

(2) Professor do Instituto de Economia da Universidade Federal de Uberlândia (UFU). Pesquisador do CNPq (Conselho Nacional de Desenvolvimento Científico e Tecnológico) e Fapemig (Fundação de Amparo à Pesquisa do Estado de Minas Gerais). Pós-Doutor - Bolsa Capes (University of Glasgow, UK). E-mail: flaviovieira@ufu.br.

(3) Professora do Instituto de Economia da UFU. Doutoranda em Economia (IE-UFU), Uberlândia, MG, Brasil. E-mail: michele@ie.ufu.br.

Economia e Sociedade, Campinas, v. 18, n. 3 (37), p. 513-546, dez. 2009. 
próximos cinquenta anos, a principal força na economia global, superando o grupo de países desenvolvidos que formam o G-6 (Estados Unidos, Japão, Alemanha, Reino Unido, França e Itália) em termos de crescimento do PIB (Produto Interno Bruto), renda per capita e movimentos comerciais e financeiros. Nesse sentido, tais economias, em função do tamanho geográfico, população e nível de produto, têm se tornado alvo de crescente interesse, principalmente em termos das lições que podem ser apreendidas por meio do estudo dos determinantes básicos do atual desempenho econômico e do potencial de tais países de se tornarem os principais impulsores do crescimento econômico mundial.

O presente trabalho pretende investigar os principais condicionantes dos níveis de crescimento econômico verificados pelos países que compõem o BRIC e a África do Sul ao longo dos últimos anos. A relevância da pesquisa está associada à importância que estas economias têm revelado no comércio mundial e na atração de fluxos de investimentos, e à posição relativa que as mesmas ocupam no conjunto das chamadas economias emergentes. Além disso, deve-se destacar as diferenças significativas em termos de desempenho econômico entre tais países, sendo que China e Índia têm recebido atenção especial no período mais recente em função de suas excepcionais taxas de crescimento econômico, que diferem significativamente quando comparadas com Brasil, Rússia e África do Sul, ao se tomar como referência o período pós-década de 1990.

O trabalho encontra-se dividido em três seções, além desta introdução e das considerações finais. A seção 1 sistematiza, sob o ponto de vista teórico e empírico, alguns dos principais trabalhos da literatura de crescimento econômico. A seção 2 está focada na análise de alguns estudos relacionados ao crescimento econômico para os países do BRIC e África do Sul. A seção 3 desenvolve uma análise comparativa de algumas variáveis associadas ao crescimento econômico destes países e uma investigação econométrica onde são estimados modelos de vetores autoregressivos (VAR) para cada uma das cinco economias, no intuito de se apreender quais são os principais condicionantes do crescimento econômico, utilizando-se do instrumento da análise de decomposição de variância (ADV).

\section{Crescimento econômico: fundamentos teóricos e evidências empíricas}

As últimas décadas têm revelado um aumento significativo de trabalhos na temática de crescimento econômico com desenvolvimentos em termos teóricos, como pode ser atribuído aos Modelos de Crescimento Endógenos, e empíricos, com o uso de novas técnicas econométricas, séries de dados temporalmente mais longas e bancos de dados mais complexos em termos de novas variáveis 
disponíveis. ${ }^{4} \mathrm{O}$ crescimento econômico tem sido parte da atenção de pesquisas, dado constituir-se em aspecto de interesse não apenas na área acadêmica, mas também nos chamados círculos políticos e em outras áreas de pesquisa, como redução de pobreza e desenvolvimento econômico. Cabe destacar que o crescimento econômico não deve ser visto como uma panacéia, mas é certamente um dos principais elementos econômicos a serem enfatizados pelos países tanto desenvolvidos como em desenvolvimento, o que se justifica pelo fato de ser considerado um dos indicadores mais importantes ao se analisar o desempenho econômico de um país, ainda que este, em termos macroeconômicos, dependa de vários elementos, como a taxa de inflação e o ajuste das contas externas, entre outros. Um dos estudos pioneiros sobre crescimento é atribuído a Solow (1956), que desenvolveu o chamado modelo neoclássico de crescimento econômico. Através de um exercício de contabilidade identificou que a acumulação de capital e o aumento da taxa de participação da força de trabalho têm um efeito relativo menor quando comparado com a contribuição da tecnologia (exógena nesse tipo de modelo) na explicação do crescimento do produto per capita. ${ }^{5}$ Sob uma perspectiva histórica, é possível argumentar que, ao longo dos anos 1950 e 1960, a teoria do crescimento esteve associada primordialmente ao modelo neoclássico nas linhas e modelos desenvolvidos por Ramsey (1928), Solow (1956), Swan (1956), Cass (1965) e Koopmans (1965). Tais modelos tinham por base a chamada propriedade de convergência, cuja ideia era de que para economias com níveis mais baixos de PIB per capita, maiores seriam as taxas de crescimento previstas, sendo essa propriedade associada ao suposto de retornos decrescentes do capital. A partir dos anos 1980, o conceito de capital nos modelos neoclássicos foi ampliado para incorporar não apenas capital físico, mas também capital humano, como pode ser visto através dos modelos desenvolvidos por Lucas (1988) e Rebelo (1991). ${ }^{6}$

Romer (1995) destaca o dilema teórico e empírico encontrado na literatura sobre crescimento e a contribuição da teoria do crescimento endógeno para se

(4) Ver Romer (1996) e Barro (1995) para uma descrição detalhada dos modelos e teorias de crescimento e como estes têm se desenvolvido a partir do trabalho de Solow (1956). Mais recentemente, diversos trabalhos, entre eles, Acemoglu; Johnson e Robinson (2005), desenvolveram estudos empíricos sobre crescimento, com o uso de dados de variáveis não apenas econômicas, mas também políticas, como corrupção, regra da lei, entre outros.

(5) O presente trabalho não tem por objetivo reproduzir o mesmo tipo de análise empírica dos trabalhos que testam o modelo de Solow ou a teoria do crescimento endógeno. A ideia é utilizar o instrumental de modelos de vetores autoregressivos (VAR) para testar as contribuições relativas de algumas variáveis selecionadas na explicação do crescimento dos países do BRIC e África do Sul, ainda que a escolha destas variáveis tenha sido feita com base na literatura sobre crescimento. Considera-se ainda que a mesma tem se diversificado de maneira significativa, incluindo variáveis como taxa de câmbio, medidas de abertura comercial e financeira, contempladas na parte empírica ao se incluir a taxa de câmbio real efetiva, os fluxos de IDE, a abertura comercial, a taxa de juros real, entre outros.

(6) Ver Barro e Sala-i-Martin (1995, cap. 5). 
entender o crescimento de longo prazo, argumentando que a principal contribuição dessa abordagem é prover uma teoria do progresso técnico, um dos elementos centrais ausentes do modelo de crescimento neoclássico. A inclusão de uma teoria da mudança tecnológica no arcabouço neoclássico, no entanto, é difícil, dado que os supostos de competitividade convencionais não podem ser mantidos.

Barro (1995) desenvolveu um estudo com dados de painel para um conjunto de mais de cem países no período de 1960 a 1990. Os resultados empíricos sugerem que, dado um nível de renda real per capita, a taxa de crescimento é positivamente afetada pelo nível de escolaridade e expectativa de vida, pela baixa fertilidade, menores gastos com consumo governamental, pela manutenção da regra da lei, menores taxas de inflação, melhoria nos termos de troca, e, negativamente, pelo nível inicial do PIB real per capita. ${ }^{7}$ A taxa de inflação não só tem um impacto negativo sobre a taxa de crescimento do PIB real no longo prazo como também sobre a taxa de investimento, mas tal resultado é estatisticamente significativo quando as economias com histórico de alta inflação são incluídas na amostra. ${ }^{8}$ Knight; Loayza e Villanueva (1993) testam o modelo neoclássico de crescimento para 98 países, de 1960 a 1985, no intuito de estabelecer a importância relativa para o crescimento de fatores que são específicos aos países e que variam no tempo, como é o caso do capital humano, investimento público e grau de abertura. Os resultados empíricos encontrados indicam que tais fatores têm um papel relevante e positivo para o crescimento. ${ }^{9}$

Outros estudos sobre crescimento tentam estabelecer uma possível relação entre crescimento e grau de abertura, como em Chang et al.(2005), destacando que tal relação depende de reformas complementares que ajudam as economias a melhorar suas vantagens competitivas internacionais. Em termos empíricos, o estudo adota uma especificação para a regressão do crescimento do PIB real com a interação entre abertura comercial e investimento em educação, inflação infraestrutura pública, estruturação do sistema financeiro, grau de flexibilidade do mercado de trabalho, dificuldade para as firmas entrarem e saírem do mercado. Os resultados obtidos indicam que a abertura tem um impacto positivo no crescimento quando outras reformas complementares são implementadas. Quanto à relação entre regimes cambiais e crescimento, Dubas et al. (2005) investigam, a partir de

(7) Lee e Barro (2001) investigaram os determinantes da qualidade educacional, constatando que os resultados indicam que a renda familiar e a educação dos pais têm efeitos significativos no desempenho dos estudantes e que, portanto, uma melhoria nos recursos escolares são fatores cruciais para atingir melhores resultados educacionais.

(8) Ver Bruno e Easterly (1995) para evidências adicionais entre inflação e crescimento.

(9) A escolha das variáveis a serem utilizadas na parte econométrica do trabalho envolvem variáveis como a taxa de inflação, taxa de crescimento populacional, nível de renda inicial do país, para se captar a ideia de tamanho em relação aos EUA, grau de abertura comercial, taxa de câmbio real efetiva, taxa de investimento, fluxos de capitais (IDE), entre outras a serem especificadas na seção 3 do trabalho. 
uma classificação De Facto e não De Jure de regimes cambiais, os resultados empíricos, que indicam que tal relação é mais estreita para o caso de regimes mais rígidos, ou seja, quando a taxa de câmbio (nominal ou real) é mais estável, o que na literatura é também conhecido como casos onde os países têm o chamado medo da flutuação. ${ }^{10}$

A liberalização da conta de capital e suas possíveis relações com o crescimento têm sido investigadas pela literatura. Entre os diversos estudos nessa linha, Klein (2005) investiga a relação entre liberalização da conta de capitais, qualidade institucional e crescimento, indicando que o efeito de um aumento na mobilidade de capitais sobre o crescimento depende do ambiente onde tais políticas são implementadas, para um conjunto de setenta e um países, sendo que melhorias institucionais ressaltam o impacto da liberalização financeira sobre o crescimento.

Um dos estudos centrados no crescimento econômico da América Latina é o de Calderon et al. (2005), que destacam que a região teve experiências de reversões do crescimento econômico em função das diversas crises dos anos 1990, além do fato de que várias reformas econômicas postergadas ou implementadas de forma incompleta, e problemas com inadequada administração macroeconômica contribuíram para um desempenho relativo desfavorável, quando comparado com outras economias, como, por exemplo, as asiáticas. Taylor (1998) examina a relação entre crescimento e distorções de preços na América Latina de 1930 a 1980, além de destacar os custos associados às estratégias voltadas para dentro em contraposição com as experiências de várias economias onde a estratégia foi ampliar a abertura comercial e estimular as exportações. Ao longo do período analisado, as economias latino-americanas não foram caracterizadas por um elevado grau de abertura, e os resultados indicam a ocorrência de diversas distorções em termos de preços e crescimento com um impacto negativo sobre o crescimento.

Aizenman (2005) analisa a liberalização financeira na América Latina nos anos 1990 e destaca que a ocorrência de diversas crises (México 1994-95, Brasil 1999 e Argentina 2001) contribuiu para a redução do otimismo sobre o papel a ser desempenhado pela liberalização financeira. Os resultados indicam um certo ceticismo sobre os efeitos benéficos do financiamento externo para estimular um crescimento sustentável de longo prazo sob tais circunstâncias, ainda que se reconheçam os efeitos positivos do processo de liberalização financeira sobre o crescimento.

(10) A classificação De Jure refere-se ao tipo de regime cambial que é declarado pelos países junto ao FMI (Annual Report on Exchange Arrangements and Exchange Restrictions), ainda que, na prática, o regime cambial não seja compatível com o que foi declarado. Neste sentido, faz-se necessário construir uma classificação De Facto. 
A análise dos diferentes estudos da literatura teórica e empírica sobre crescimento fornece subsídios importantes para a investigação mais detalhada dos países que compõem o BRIC e a África do Sul na seção subsequente do trabalho, além de servir como referencial na escolha das variáveis para cada um desses países na investigação econométrica da seção 3. Entre as variáveis para os modelos de crescimento do PIB real, algumas estão associadas aos modelos convencionais de crescimento, como é o caso da taxa de crescimento populacional e a renda per capita inicial em relação à renda dos EUA para se analisar elementos de convergência. Outras variáveis destacadas pela literatura empírica são incorporadas à análise, tais como a inflação, a taxa de câmbio (nominal e real), as exportações e o grau de abertura, a taxa de juros e a taxa de investimento, além dos fluxos de IDE e do endividamento.

\section{Crescimento e principais condicionantes: Brasil, Rússia, Índia, China (BRIC) e África do Sul}

O objetivo da presente seção consiste em apresentar uma síntese da literatura sobre os principais fatores que explicam as taxas de crescimento vivenciadas ao longo das últimas décadas pelos países que compõem o BRIC.

\subsection{China}

A economia chinesa tem se destacado, no período recente, por apresentar elevadas taxas de crescimento quando comparada às demais economias em desenvolvimento (taxa média de crescimento do PIB igual a 10\% nos anos $1990 \mathrm{e}$ $9,4 \%$ entre 2000 e 2005).

Andrade (2006) aponta, entre os principais condicionantes do elevado crescimento chinês, as altas taxas de investimento, uma maior abertura comercial, política de estímulos favoráveis às exportações e à atração de investimentos externos, a manutenção de um regime cambial rígido e favorável ao desempenho do setor externo a partir de meados dos anos 1990 e os investimentos em capital humano. Cabe ressaltar ainda o papel desempenhado pelos controles de capitais e o câmbio administrado como elementos que favoreceram o crescimento chinês, e que, no caso dos controles de capitais, serviu como política de proteção a choques externos e possível volatilidade dos fluxos de capitais. O autor observa que as elevadas taxas de crescimento estão atreladas às altas taxas de poupança e investimento, e que a formação bruta de capital fixo apresentou um crescimento recorrente nos anos 1990, atingindo 40\% em 2003, com um comportamento similar da taxa de poupança, também acima dos $40 \%$ nos anos 1990 e 2000.

O investimento em capital humano apresentou razoável crescimento (4,28\%) no período de 1953 a 1999 de acordo com Wang e Yao (2003). Heckman 
(2005), no entanto, ressalta o desequilíbrio existente entre investimento em capital físico e capital humano na China. A razão entre investimento em capital físico e capital humano é alta. Em 1995 a China gastou aproximadamente 2,5\% do PIB em escolaridade e $34 \%$ em acumulação de capital físico. No entanto, a parcela da população com nível superior foi igual a 4,7\% em 2002, relativamente baixa se comparada com alguns países desenvolvidos onde esta proporção excede $30 \%$. O autor aponta uma taxa de retorno da educação na China de $7 \%$ nos anos recentes, muito abaixo da taxa de $20 \%$ de retorno do capital físico.

Cabe destacar que, segundo Rodrik (2006a), a China não seguiu de maneira rígida várias das recomendações sugeridas para uma maior integração global. Na realidade, as políticas chinesas têm sido até certo ponto morosas e específicas, com uma abertura comercial gradual e com defasagens em várias reformas comerciais e financeiras. Ainda permanecem em vigor várias barreiras tarifárias, não tarifárias e licenças comerciais, além de determinados controles sobre os fluxos de capitais, principalmente sobre os de curto prazo.

Sobre o comércio exterior, observam-se a ampliação da participação chinesa no comércio internacional (6\% do comércio mundial em 2003), o aumento do grau de abertura da economia (soma das exportações e importações em relação ao PIB) e sucessivos superávits na balança comercial. Lai (2004) sugere que a trajetória ascendente da relação exportações de bens e serviços/PIB decorre de mudanças no ambiente econômico chinês. Destacam-se as reformas orientadas para o mercado, a adoção de políticas comercial e cambial apropriadas, investimentos diretos originados de Hong Kong e Taiwan e de corporações multinacionais, o aumento nas importações de bens de capital e na eficiência das indústrias manufatureiras.

Andrade (2006) destaca que a política comercial chinesa se desenvolveu de acordo com as linhas de outros países asiáticos, restringindo importações e incentivando as exportações, principalmente o processamento e a exportação de produtos intermediários importados. Nesse sentido, muitas empresas da região Ásia-Pacífico se lançaram no mercado chinês em busca de vantagens em termos de baixo custo da mão de obra e de impostos para montagem e reexportação. Em 2000, verifica-se uma alteração do perfil das exportações chinesas, passando a predominar as exportações de produtos manufaturados (89\% das exportações totais), aumentando a proporção de bens associados à mão de obra qualificada e insumos tecnológicos. Rodrik (2006a) ressalta que o perfil das exportações chinesas direcionado para produtos mais sofisticados, com elevados níveis de 
produtividade, consistiu, de forma mais significativa que o volume exportado, em um dos principais fatores explicativos do rápido crescimento chinês. ${ }^{11}$

O regime cambial chinês tem se caracterizado, desde 1994, pela rigidez da taxa de câmbio ( 8,28 yuan/dólar), configurando um importante instrumento de estímulo às exportações, cujo desempenho está diretamente atrelado às elevadas taxas de crescimento econômico. A atual taxa de câmbio é considerada desvalorizada em termos reais (De Paula; Ferrari Filho, 2006) e encontra-se distante do chamado nível de equilíbrio. Nos anos mais recentes, existem recorrentes pressões para que a China transite para um regime de câmbio mais flexível, ainda que tal flexibilização deva ser implementada em consonância com medidas em direção a um sistema financeiro mais sólido e eficiente e a uma maior liberalização da conta de capitais. Caso ocorra a flexibilização do regime cambial chinês, tal mudança deve vir acompanhada de uma apreciação da taxa de câmbio (nominal e real). ${ }^{12}$

Os fluxos de investimento direto estrangeiro (IDE) tiveram um crescimento significativo a partir do início dos anos 1990. Em 2002 e 2003, a economia chinesa passou a receber IDE em torno de US\$ 47 bilhões, atingindo patamares superiores a US\$ 100 bilhões em 2006 e 2007. Quanto aos fluxos de portfólio, a oscilação é mais significativa, alternando anos de entrada significativa, como em 2003, com períodos de saída, entre 1999 e 2002 (pós-crise asiática). De Paula e Ferrari Filho (2006) argumentam que a atração de IDE foi favorecida pelas perspectivas de bons negócios a longo prazo e pelo fato de que as políticas de liberalização para os fluxos de IDE começaram mais cedo, impondo à China pouco controle sobre os mesmos. Por outro lado, os empréstimos externos tiveram menor crescimento em função da existência de restrições à contratação de empréstimos do exterior. Portanto, ao mesmo tempo em que procurou atrair IDE, a China foi bastante cautelosa em administrar os empréstimos externos e os capitais de portfólio.

Fogel (2006) sugere que a China tem condições de manter as atuais taxas de crescimento (média de 9\%) nos próximos anos, uma vez que as condições favoráveis ao crescimento ainda se encontram presentes. $\mathrm{O}$ autor acredita que os graves problemas políticos, econômicos e internacionais vivenciados pelo país, tais como ineficiência do sistema bancário e das empresas estatais, tensões com parceiros comerciais devido ao câmbio desvalorizado, as disparidades regionais e

(11) Rodrik (2006a) destaca o papel do IDE para a evolução da indústria chinesa na medida em que a entrada dos investidores estrangeiros foi permitida mediante a ocorrência de joint ventures e transferência de tecnologia para as firmas domésticas, o que possibilitou a produção e a exportação de uma cesta de produtos mais sofisticados.

(12) Ver Frankel (2005) para uma discussão detalhada sobre o grau de desalinhamento (depreciação) real efetivo da taxa de câmbio chinesa e as pressões para uma flexibilização do regime cambial chinês. 
entre o trabalho altamente qualificado e o trabalho manual, problemas de infraestrutura (energia elétrica e combustíveis) e poluição ambiental, poderão ser resolvidos ao longo do tempo, o que permitirá a manutenção do crescimento no longo prazo.

\section{2 Índia}

A economia indiana também vem apresentando, nas últimas décadas, notável desempenho macroeconômico, caracterizado por elevadas taxas de crescimento do PIB (média de 5,7\% nos anos 1990 e de 6,3\% entre 2000 e 2005), baixa inflação e crescimento expressivo das exportações de bens e serviços, especialmente de serviços relacionados à tecnologia da informação.

O desempenho econômico indiano encontra-se, por vezes, associado às reformas implementadas na Índia no início da década de 1990, com ênfase na liberalização comercial, na abertura ao investimento direto estrangeiro, na modernização do sistema financeiro e na redução dos monopólios do setor público. Entretanto, DeLong (2003), Rodrik e Subramanian (2004), Kochhar et al. (2006) e Nassif (2006) apontam que a transição para o alto crescimento teria se iniciado já em meados dos anos 1980, uma década antes das medidas de liberalização econômica. Tais autores argumentam que a base do crescimento indiano fundamenta-se no período 1985-1990, no qual, para romper com um cenário protecionista de uma indústria ineficiente e com baixa competitividade no mercado internacional, diversas medidas foram adotadas pelo governo Rajiv Ghandi para estimular as vendas externas: eliminação gradual dos licenciamentos industriais e das licenças de importação, incentivos às exportações, redução dos direitos de monopólio do governo na importação de itens estratégicos, minirreforma tributária, com dedução ou isenção de impostos sobre o valor adicionado dos insumos produzidos no mercado interno ou importados.

Para Nassif (2006), o desempenho notável da economia indiana pode ser considerado como resultado da combinação de três fatores: i) continuidade das reformas estruturais iniciadas nos anos 1980 para propiciar o aumento da produtividade na economia; ii) política macroeconômica voltada ao crescimento e à geração de empregos; e iii) uma visão estratégica de longo prazo, que mantém o planejamento e a presença do Estado em setores economicamente pouco atrativos à livre iniciativa.

Nesse contexto, o processo de liberalização da economia ganhou continuidade nos anos 1990 através da adoção de medidas como a extinção dos controles de licenciamento industrial; a quase completa eliminação dos licenciamentos para as importações; maxidesvalorização nominal em relação ao dólar e a criação de um mercado dual de câmbio para manter a competitividade 
externa dos bens e serviços indianos comercializáveis; privatização das empresas públicas menos relevantes; liberalização do IDE, mas adoção de medidas mais prudentes quanto à eliminação dos entraves à entrada de capitais de curto prazo; reforma do sistema financeiro e do mercado de capitais, com desregulamentação bancária, simplificação dos mecanismos de determinação das taxas de juros domésticas; eliminação de restrições à emissão de ações no mercado primário e permissão (sujeita a restrições) para que investidores institucionais estrangeiros pudessem aplicar em ações de companhias indianas.

$\mathrm{O}$ autor, no entanto, destaca que a estratégia indiana para o crescimento envolveu a atuação estatal em questões que abarcam um conjunto de políticas mais amplas, como a industrial, a comercial, a de infraestrutura, a tecnológica, a educacional etc., em uma visão de desenvolvimento de longo prazo, onde o Estado continua atuando em setores estratégicos, notadamente em infraestrutura. Além desses mecanismos de liberalização e de incentivos às vendas externas, Nassif (2006) sugere que a expansão dos déficits fiscais decorrentes das políticas de expansão de gastos públicos pode ter contribuído para elevar as taxas médias de crescimento econômico, porém a geração de déficits fiscais futuros acabou por ter impactos desfavoráveis sobre o crescimento.

Velasco (2005) ressalta o caráter pragmático assumido pelas reformas implementadas na Índia, já que as mesmas foram realizadas de forma gradual, flexível e de acordo com os interesses do país. Apesar de expressiva redução, a Índia mantém altos níveis de proteção tarifária, comparativamente, e as barreiras não tarifárias continuam a valer para a importação de bens de consumo e produtos agrícolas. Além disso, as reformas indianas destacam-se pelo descompromisso com fórmulas pré-fabricadas - a Índia não defende a independência do Banco Central; não há eliminação total dos controles de capitais; permanece a forte participação estatal no setor bancário; e, ao invés de grandes programas de privatização, o Estado procurou reestruturar o setor produtivo estatal mediante uma política cautelosa de desinvestimento (venda de participações, sem transferência de controle sobre as empresas).

Bosworth et al. (2007) destacam que o desempenho da economia indiana, de maneira distinta em relação à economia chinesa, se fundamenta na rápida expansão do setor de serviços. A participação desse setor na composição do valor adicionado total avançou consideravelmente nas últimas décadas, representando $58 \%$ do PIB em 2003. Esse fato contribuiu para a expansão do setor de serviços, especialmente de tecnologia de informação, e para uma política industrial destinada a fomentar a eficiência por meio da liberalização das importações de equipamentos. 
Sobre a taxa de acumulação de capital fixo, os autores indicam uma tendência de crescimento da taxa de investimento (17\% do PIB entre 1999-2004), sendo que a taxa de poupança requerida para financiar o investimento na economia também tem aumentado rapidamente. Destaca-se que a economia indiana vem tentando capturar poupança externa, através do IDE, mas o país tem recebido muito pouco dos fluxos de IDE direcionados para os países emergentes. Quanto à formação de capital humano, verifica-se que a Índia ainda enfrenta sérios desafios no sistema educacional, principalmente no que diz respeito à educação primária. As taxas de analfabetismo no país permanecem bastante elevadas (40\%), com porcentagem de trabalhadores com educação secundária e nível superior igual a 14\% e 6\%, respectivamente, em 2004.

De Paula e Ferrari Filho (2006) destacam o aumento do fluxo de IDE para a Índia após os anos 1990, embora este ainda permaneça relativamente baixo. As regulamentações sobre os fluxos de capitais de longo prazo têm sido afrouxadas, incluindo os limites de propriedade acionária no IDE e os limites para captação de empréstimo externo pelas firmas domésticas. As restrições sobre capitais de curto prazo continuam, no entanto, significativas, predominando controles quantitativos e sobre a saída de capital.

Finalizando, Nassif (2006) observa que não há evidências precisas de que o atual processo de crescimento da economia indiana será sustentável no longo prazo. Dependerá, sobretudo, da capacidade do setor de serviços e industrial de produzir maiores efeitos de encadeamento entre si e com a agricultura, que ainda absorve cerca de $60 \%$ da força de trabalho, de forma que venham a aumentar o potencial de absorção da força de trabalho excedente no país.

\subsection{Rússia}

A economia russa, a partir de 1999, com o governo Putin, iniciou uma fase de rápida expansão econômica. No período mais recente, o país vem apresentando expressivas taxas de crescimento do PIB (média de 6,7\% entre 1999 e 2005), taxas de inflação declinantes, contas fiscal e corrente superavitárias, além de um alto volume de reservas internacionais. ${ }^{13}$

A literatura indica que o crescimento do PIB russo esteve apoiado nos preços mais altos do petróleo (o preço médio do petróleo no mercado internacional aumentou de US\$17,9 em 1999 para US\$ 66,5 em 2006, atingindo valores próximos a US\$ 100 em 2007), na moeda desvalorizada, no aumento da produção

(13) Para Berengaut e Elborgh-Woytek (2005), o desempenho recessivo no período 1990-1998 está relacionado à transição de uma economia centralizada e planificada para uma economia de mercado, marcada por privatizações em um contexto de inexistência de regras e leis sobre direitos à propriedade, liberalização dos preços, abertura comercial e liberalização da conta de capital. 
nos setores industrial e de serviços, e no fortalecimento do mercado interno (IMF, 2007; De Paula; Ferrari Filho, 2006; World Bank, 2005). O esforço governamental para fazer avançar as reformas estruturais contribuiu para aumentar a confiança das empresas e dos investidores nas perspectivas russas, favorecendo o processo de aceleração do crescimento econômico (Owen; Robinson, 2003). Além disso, o próprio governo declarou o objetivo de dobrar o PIB em dez anos, por meio de uma estratégia de médio prazo de desenvolvimento econômico e social baseada na maximização do crescimento econômico e na diversificação da economia para além dos produtos baseados em recursos naturais, a fim de limitar os riscos decorrentes da dependência dos preços internacionais do petróleo.

A elevação dos preços e do volume dos recursos naturais exportados pela Rússia - petróleo, gás, eletricidade e hidrocarbonetos - consistiu no fator que mais contribuiu para a rápida recuperação pós-crise de 1998, resultando em um acúmulo na balança comercial com um superávit próximo a US $\$ 250$ bilhões entre 1999 e 2003 (De Paula; Ferrari Filho, 2006). Contudo, a aceleração do crescimento da economia russa envolve outros determinantes não estruturais. Nesse sentido, verifica-se que as mudanças nos principais preços relativos da economia russa acarretaram uma reação endógena à crise e ajudaram a despertar o crescimento. A desvalorização da taxa de câmbio nominal (rublo/dólar), de 5,8 para 24,6, além de estimular o setor exportador, ajudou a manter o alto crescimento da produção por meio de um processo de substituição de importações. Por outro lado, o aumento dos salários reais acima da evolução do PIB e o declínio das taxas de juros possibilitaram a ocorrência de um boom de consumo doméstico. Mudanças no comportamento dos formuladores de política, decorrentes da experiência de alta inflação e moratória, conduziram a uma política monetária mais restritiva, o que forçou uma política de superávit orçamentário através de um forte ajuste fiscal da ordem de 10\% do PIB entre 1997 e 2001, de redução da dívida e de administração da taxa de câmbio (Owen; Robinson, 2003; World Bank, 2005; IMF, 2007).

De Paula e Ferrari Filho (2006) indicam que a recente melhoria nos indicadores de vulnerabilidade externa da Rússia decorre fundamentalmente do desempenho da balança comercial e da elevação das reservas cambiais. Com relação aos fluxos de capitais, verifica-se que a conta de capital russa é parcialmente conversível, com controles sobre entrada e saída. Recentemente o governo liberalizou as transações cambiais, embora tenha adotado requerimentos de reserva no fluxo de entrada. Os fluxos de curto prazo tornaram-se positivos somente em 2003, já que os fluxos de saída de capitais compensavam significativamente os empréstimos externos feitos pelos bancos e pelo setor corporativo russo. Os fluxos de IDE permanecem pequenos devido, em parte, à 
dificuldade do ambiente de negócios no país e à predominância de transações off shore para grandes investimentos.

O estudo do Banco Mundial (World Bank, 2005) sugere que a extensão das mudanças estruturais implementadas na Rússia é mais importante do que os fatores não estruturais para a explicação do rápido crescimento de longo prazo. Há cinco dimensões para as mudanças estruturais na economia russa: i) necessidade de realocação espacial devido ao legado de industrialização e urbanização sob planejamento central; ii) realocação do emprego entre os setores da economia, especialmente da indústria para o setor de serviços; iii) reestruturação intrassetorial, especialmente na indústria, gerando maiores ganhos de produtividade; iv) redução do tamanho das antigas unidades e criação de novas empresas (pequenas e médias) para melhorar a produtividade; v) desconcentração da propriedade, pois a propriedade na indústria é dominada por grandes proprietários privados e é concentrada em setores estratégicos (petróleo, matériasprimas, automóveis e químicos). Nesse contexto, o papel do Estado consistiria em alimentar a mudança estrutural e consolidar os efeitos de uma economia de mercado mais dinâmica através do estabelecimento de regras e de uma estrutura que incentivassem a atividade econômica e a competição.

Owen e Robinson (2003) e IMF (2007) apontam que o crescimento da economia russa no longo prazo depende da elevação do atual nível de investimento a fim de aumentar a produtividade nos diversos segmentos da economia. Nesse sentido, sugere-se que o governo avance na implementação de políticas econômicas para fortalecer a taxa de investimento doméstica e estrangeira, entre as quais: investimentos em infraestrutura, parcerias entre o setor público-privado, reformas no setor bancário e financeiro, estímulos à maior integração global, desenvolvimento das zonas econômicas especiais, além de reformas institucionais para reduzir a corrupção e a burocracia.

\subsection{Brasil}

Entre os países que compõem o BRIC, o Brasil é o que possui as menores taxas de crescimento do PIB observadas ao longo das últimas décadas (média de $1,7 \%$ nos anos 1990 e $3,1 \%$ entre 2000 e 2005).

A década de 1990, no Brasil, foi marcada pelas reformas liberalizantes abertura comercial e financeira, desregulamentação dos mercados, privatizações, redução da atuação do Estado - e pela estabilização inflacionária alcançada através do Plano Real. Entretanto, para Carneiro (2002) e Sicsú (2007), a política econômica adotada com o Real alijou o crescimento econômico em nome do fortalecimento das instituições nacionais com o propósito de controlar a inflação e atrair investidores internacionais. Mesmo após a eleição do presidente Lula, a 
condução da política econômica manteve as linhas gerais do governo anterior (FHC), adaptando apenas alguns conceitos, relacionados à área social, aos princípios do Partido dos Trabalhadores.

Carneiro (2002) destaca uma conjugação de fatores internos e externos, que determinaram o baixo dinamismo da economia brasileira no período recente. A estratégia de "desenvolvimento" do Real foi baseada nos seguintes aspectos: i) a estabilidade de preços estimularia o investimento privado; ii) a abertura comercial, junto com o câmbio sobrevalorizado, disciplinaria os produtores domésticos, conduzindo a ganhos de eficiência; iii) as privatizações e o investimento estrangeiro removeriam gargalos de oferta na indústria e infraestrutura e iv) a liberalização cambial atrairia poupança externa para complementar o investimento doméstico e financiar o déficit em conta corrente.

$\mathrm{O}$ autor argumenta que, embora a estabilidade de preços tenha sido alcançada, a abertura comercial causou a deterioração do saldo comercial e o desequilíbrio do balanço de pagamentos, tornando a economia bastante dependente de recursos externos. A política de taxa de juros elevada e a concorrência com os produtos importados ocasionaram a quebra de muitas empresas nacionais e o aumento do nível de desemprego. A liberalização da conta de capital não resolveu o problema do financiamento de longo prazo, uma vez que a maioria dos fluxos de capitais que ingressaram no país, até meados da década de 1990, foi de curto prazo, em busca de ganhos rápidos e elevados. Mesmo após 1995, quando os fluxos de IDE passaram a ingressar mais fortemente na economia, tais fluxos não foram capazes de alavancar o crescimento, pois se dirigiram, principalmente, à compra de empresas privatizadas e, portanto, não implicaram a criação de riqueza nova (investimento no setor produtivo) para a economia. A ausência de regulação dos fluxos de capitais implicou volatilidade do financiamento, vulnerabilidade da economia aos fluxos de curto prazo e restrições à autonomia da política econômica doméstica.

A mudança do papel do Estado também é relevante para explicar o baixo crescimento econômico brasileiro. Observa-se que o Estado, com a privatização das empresas estatais, deixou de atuar diretamente no desenvolvimento do setor produtivo, na criação de infraestrutura e no financiamento de setores específicos, como o fez no período de maior crescimento da economia (anos 1960 e 1970). Atualmente, o Estado perdeu sua capacidade de coordenação e de indução do investimento. A preocupação básica passou a ser a redução do déficit público, agravado pelo elevado componente financeiro da dívida, por meio da obtenção de crescentes superávits primários, o que implica cortes de gastos públicos e redução de recursos para os projetos sociais e de investimentos (Carneiro, 2002; Sicsú, 2007). 
A partir de 1999, a estratégia brasileira passou a ser fundamentada no tripé metas de inflação, metas fiscais e flexibilidade cambial. O objetivo principal do governo, no entanto, continua sendo a manutenção da estabilidade inflacionária baseada na obtenção de credibilidade e de reputação perante os mercados financeiros domésticos e internacionais (Sicsú, 2007). Para manter a inflação controlada, conforme a meta, as taxas de juros reais brasileiras foram mantidas em patamares elevados, acima dos $10 \%$ no período 1999-2005, dificultando a obtenção de crédito e a formação de expectativas de longo prazo pelos empresários, além de aumentar a dívida pública. Quanto ao regime cambial, verifica-se certa volatilidade da taxa de câmbio nominal, que aumenta em períodos de forte pressão cambial, além do fato de que o câmbio real efetivo deprecia ou aprecia em função do movimento dos fluxos cambiais. A partir de meados de 2004, verifica-se uma clara tendência de apreciação cambial (De Paula; Ferrari Filho, 2006).

De Paula e Ferrari Filho (2006) afirmam que, após 2002, o crescimento das exportações líquidas brasileiras implicou uma melhoria significativa dos indicadores de vulnerabilidade externa com a diminuição da relação dívida externa/exportações de 3,5 em 2002 para 2,1 em 2004. Adicionalmente, o peso da dívida de curto prazo no total da dívida externa, a existência de uma conta de capital aberta e as dúvidas quanto à trajetória futura da balança comercial devido à tendência de apreciação do câmbio indicam que o futuro da economia brasileira é ainda preocupante.

Sobre as tendências de crescimento da economia brasileira, Wilson e Purushothaman (2003) argumentam que o processo de ajustamento da economia durante o Plano Real reduziu a taxa de investimento, o que contribuiu para a depreciação do estoque de capital, principalmente em infraestrutura, com consequências danosas sobre a produtividade da economia. Para quebrar a tendência de baixo crescimento brasileiro, sugere-se aprofundar as reformas estruturais, pois, comparados com a China, a economia é muito menos aberta, as taxas de investimento e de poupança são muito baixas, e o endividamento interno e externo é substancialmente mais alto.

Sicsú (2007) enfatiza a ausência de mudança dos rumos da política econômica no governo Lula, que se mostra incapaz de criar um programa voltado para o crescimento e geração de empregos, sem perder de vista o objetivo de controle da inflação. $\mathrm{O}$ autor acredita que, para estimular o crescimento, o governo deveria criar uma ampla arquitetura que garanta a estabilidade de preços independentemente não só da taxa de juros mas também de uma política industrial de promoção de exportações e substituição de importações e de uma política cambial responsável para restringir transações financeiras especulativas. Tais fatores possibilitariam uma queda da taxa de juros nos próximos anos e uma 
redução da vulnerabilidade da economia a choques que possam se transformar em crises cambiais.

\section{5 África do Sul}

A África do Sul, maior potência do continente africano vem, recentemente, ganhando destaque no cenário econômico internacional, tendo em vista a obtenção de uma taxa de crescimento do PIB ascendente nos anos 2000 (média de 4\% entre 2000 e 2005). Rodrik (2006b) analisa os dilemas enfrentados pela economia da África do Sul, ressaltando que, apesar das grandes transformações econômicas ocorridas no período após a transição democrática em 1994, o desempenho da economia em termos de crescimento e de redução do nível de desemprego tem estado muito abaixo de outras economias emergentes, como as da China e Índia. O autor sugere que uma das razões para os elevados níveis de desemprego está associada aos elevados níveis salariais. Adicionalmente, tanto o alto desemprego como as taxas de crescimento moderadas estão associadas à redução do chamado setor não mineral da economia nos anos 1990 e à fragilidade do setor manufatureiro voltado para as exportações, que tem vivenciado uma redução de lucratividade, fator que compromete a geração de empregos e o estímulo ao crescimento da economia.

Banerjee et al. (2007), ao analisar as razões associadas aos elevados níveis de desemprego na África do Sul, desde meados dos anos 1990, investiga se tal elevação se deve às mudanças estruturais na economia ou aos choques negativos temporários. Os resultados do modelo logit indicam que a ocorrência de choques negativos tem sido responsável pela alteração da taxa de desemprego de equilíbrio da economia sul-africana.

Outro aspecto importante analisado pela literatura sobre o desenvolvimento econômico da África do Sul diz respeito ao comportamento da taxa de câmbio e, nesse sentido, Frankel (2007) desenvolve uma investigação econométrica para o período de 1984- 2006. Os resultados indicam que os fundamentos econômicos são importantes para a determinação da taxa de câmbio e que o comportamento do índice real de preços das commodities do setor mineral da África do Sul tem impacto sobre a renda real e a taxa de câmbio associado à apreciação cambial real no período mais recente (2003 a 2006). O que ocorre é que a política de altas taxas de juros domésticas aumenta a demanda internacional pela moeda local (rand) e aprecia a taxa de câmbio, controlando a análise econométrica para fatores como inflação esperada e risco-país.

Edwards e Lawrence (2006) analisam a política de comércio exterior da África do Sul, ressaltando que, no período do apartheid, tal política foi marcada por um elevado nível de protecionismo, limitando o desempenho das exportações 
e importações. Nesse contexto, a economia sul-africana passou a depender de choques internacionais favoráveis nos preços das commodities; caso contrário, a economia sofreria sérias restrições externas. Recentemente, tendo por base vantagens de dotação de recursos naturais, o país desenvolveu uma estratégia de competitividade para produtos primários e manufaturados com algum grau de intensidade de capital. Esse desenvolvimento pode ser explicado em função do padrão de proteção tarifária que não favorece a exportação de bens manufaturados que não sejam commodities, limitando, assim, o crescimento e a diversificação das exportações. Períodos marcados por baixa demanda internacional por commodities e por queda no preço do ouro no mercado internacional acabam refletindo um baixo crescimento econômico. O processo de liberalização comercial, ocorrido a partir de meados dos anos 1990, além de exercer um impacto favorável em termos de redução de custos dos insumos, tem mostrado efeitos relevantes ao estimular o setor exportador e mesmo em relação à diversificação da pauta.

\section{Análise comparativa e estimações econométricas: determinantes do crescimento}

A seção 3 tem por objetivo apresentar uma análise comparativa das variáveis apresentadas no Apêndice (Tabelas 2A a 6A), que serviram de base para a investigação econométrica, cujos resultados encontram-se sistematizados na seção 3.2.

\subsection{Análise comparativa de indicadores relevantes ao crescimento: Brasil, China, Índia, Rússia e África do Sul}

Os dados das médias para os períodos 1980-1992 e 1993-2005 contidos nas tabelas do Apêndice, - a análise para a Rússia restringe-se ao segundo período - revelam que o desempenho das economias em termos de crescimento do PIB real é marcado por uma discrepância favorável à China e à Índia, com taxas próximas a $10 \%$ e $6 \%$, respectivamente, enquanto Brasil, Rússia e África do Sul tiveram taxas de crescimento variando entre $1,1 \%$ (Rússia) e 3,1\% (África do Sul). Comparando o primeiro com o segundo período, percebe-se que houve redução na taxa de crescimento populacional para os quatro países, considerando-se que a Rússia participa somente do segundo período, enquanto Brasil e África do Sul configuram-se como os países com maiores taxas, acima de $1,5 \%$. Ao se analisar o PIB real dos países em relação ao PIB real dos EUA entre os dois períodos, percebe-se certa estabilidade para a China, uma elevação para o Brasil, e redução para a Índia e África do Sul. Em termos de estabilidade macroeconômica, levandose em conta a inflação, Brasil e Rússia são os países com histórico inflacionário relevante, embora, recentemente (2000 a 2005), ambos os países tenham revelado significativa reversão dessa tendência, .China, Índia e África do Sul, por outro lado, demonstram baixos patamares inflacionários ao longo do período de análise. 
A análise do comportamento da taxa de câmbio real efetiva revela estabilidade para o caso brasileiro, depreciação para Índia e apreciação para China e África do Sul. Cabe ressaltar que a China, ao longo do segundo período, atrelou sua taxa de câmbio em relação ao dólar americano em um patamar desvalorizado em termos reais no intuito de favorecer o desempenho do setor exportador, o que, na prática, se mostrou uma estratégia adequada. Isso pode ser corroborado pela análise da taxa de crescimento das exportações, onde a China teve o melhor desempenho $(18,4 \%)$, comparando-se os dois períodos para os cinco países. Observa-se que todos os países tiveram elevação nessa taxa, observando-se o primeiro e o segundo período, com exceção do Brasil que apresentou uma redução de $9,0 \%$ para $8,4 \%$, com a ressalva de que, no segundo período, estão inclusos os anos iniciais do Plano Real, período em que a apreciação cambial real comprometeu o desempenho do setor exportador.

O grau de abertura apresenta uma elevação para todos os países em uma comparação entre os períodos, ainda que, para a África do Sul, esta elevação tenha sido pequena. Comparativamente, as economias menos abertas sob o ponto de vista comercial são a brasileira e a indiana, com índices inferiores a 30\%. A taxa de juros real tem um comportamento díspare entre as economias analisadas, especialmente quando se considera as duas economias com históricos inflacionários, ou seja, Brasil e Rússia, enquanto China e Índia não demonstraram alterações significativas entre os dois períodos. O que se percebe, ao analisar com mais cuidado os dados das Tabelas 2A e 6A para Brasil e Rússia, respectivamente, é que, nos anos mais recentes, a taxa de juros real brasileira oscila em torno de $10 \%$, enquanto a Rússia tem taxas muito baixas e até negativas.

Um dos aspectos centrais apontados pela literatura de crescimento em suas diversas vertentes e abordagens é a importância da taxa de investimento como fator explicativo do crescimento econômico. A análise da variável TXI revela que a taxa de investimento se manteve constante para o Brasil entre os períodos analisados (em torno de 20\%), apresentando redução no caso da África do Sul (15,8\% no segundo período), e elevação nos casos da China e Índia, com destaque para a China, onde a taxa de investimento passou de $29,2 \%$ para $36,1 \%$ na média dos dois períodos. Esse é um indicador a ser corroborado empiricamente pela análise VAR da importância de TXI para se entender o comportamento da taxa de crescimento.

Os fluxos de IDE ganharam relevância entre o primeiro e o segundo período, especialmente para o Brasil e China, e mesmo para a Índia e África do Sul, onde tais fluxos eram desprezíveis no primeiro período, atingindo 0,7\% e $1,3 \%$ do PIB no segundo período. Os indicadores de dívida em relação às exportações apresentaram redução para a China e Índia, o que pode ser explicado pela expansão das exportações, e elevação no caso do Brasil, também associados 
aos problemas de frágil desempenho exportador em parte do segundo período, explicados pela apreciação cambial real durante a estratégia de combate inflacionário através da rigidez cambial. Quanto ao perfil (curto e longo prazo) da dívida em relação às exportações, verifica-se uma redução na dívida de curto prazo para o Brasil, China e Índia entre o primeiro e segundo período. Pode-se dizer que o endividamento é um problema associado primordialmente ao Brasil, mas menos relevante para as demais economias.

\subsection{Investigação econométrica: modelos VAR}

O objetivo desta seção é analisar os determinantes do crescimento por meio da estimação dos modelos de Vetores Autoregressivos (VAR) e do instrumental da Análise de Decomposição de Variância (ADV) para o Brasil, Rússia, Índia, China e África do Sul. Em todos os países (exceto Rússia), o período de análise é de 1980 a 2005, com dados anuais. Para a Rússia, o período restringe-se de 1993 a 2005 em função da indisponibilidade de dados. A ausência de dados limita a análise VAR para a Rússia a apenas uma defasagem, enquanto para as demais economias a escolha foi feita com defasagens de um a três. Inicialmente, foi desenvolvido o teste de estacionariedade ADF, além da escolha das defasagens dos modelos VAR pelo critério de Schwarz, para, na sequência, serem estimados os modelos em suas distintas especificações (modelos 1, 2 e 3). As variáveis utilizadas nas estimações dos modelos VAR estão descritas na Tabela 1A do Apêndice, com exceção de TAM, X, TC e os indicadores de dívida, cujo propósito se limitou apenas à análise comparativa dos dados desenvolvida anteriormente. Os três modelos estimados são os seguintes:

Modelo 1: TCPIB, TXI, INF, TCPOP, TRADE

Modelo 2: TCPIB, TXI, TJREAL, TCREF, TRADE

Modelo 3: TCPIB, IDE, INF, TCPOP, TCX

A ideia do modelo 1 é estimar um VAR com base nas variáveis básicas associadas aos modelos de crescimento neoclássico (TXI e TCPOP), com a inclusão da variável (INF) para captar estabilidade macroeconômica e o grau de abertura (TRADE). No modelo 2, ao se utilizar a TCREF e a TJREAL, optou-se por excluir a INF, pois os preços relativos estão presentes no cálculo da taxa de câmbio real e da taxa de juros real, além da taxa de crescimento populacional, dado que seria adequado um modelo onde o câmbio real efetivo fosse estimado em conjunto com o grau de abertura. ${ }^{14} \mathrm{O}$ modelo 3 inclui os fluxos de capitais (IDE) sem, no entanto, incluir TXI, pois a formação bruta de capital fixa é em parte

(14) Cabe ressaltar que, como a estimação do VAR da Rússia só pode ser feita com uma defasagem e com todas as variáveis em nível devido ao número limitado de observações, um dos critérios de comparabilidade dos resultados da análise VAR entre as cinco economias foi o de limitar o número de variáveis a cinco em cada um dos três modelos.

Economia e Sociedade, Campinas, v. 18, n. 3 (37), p. 513-546, dez. 2009. 
explicada pela entrada de recursos externos. A taxa de crescimento das exportações (TCX), neste caso, é considerada em substituição ao grau de abertura (TRADE) utilizado nos dois modelos anteriores, mas sem a taxa de câmbio real efetiva em função da inclusão da taxa de inflação

Os testes de estacionariedade de Dickey-Fuller Aumentado (ADF) foram implementados para os quatro países, com exceção da Rússia, onde se trabalhou com todas as variáveis em nível devido ao problema do reduzido número de anos. Foram incluídos cinco termos defasados em primeira diferença, e a seleção do número de defasagens seguiu o critério de Schwarz. Assim, a tabela 1 sistematiza, para cada um dos países, a ordem de integração das variáveis a serem utilizadas na estimação do VAR, I(0) ou I(1). Os resultados indicam se as séries são estacionárias em nível ou em primeira diferença respectivamente. Além disso a Tabela 1 sistematiza a escolha das defasagens do VAR (1 a 3) nos diversos modelos estimados para os quatro países, já que o VAR para a Rússia não envolveu escolha de defasagens, pois só foi possível estimar o VAR (1). ${ }^{15}$

Tabela 1

Ordem de integração das variáveis e defasagens do VAR nos três modelos

\begin{tabular}{l|c|c|c|c|c|c|c|c|c}
\hline Variáveis & TCPIB & TCREF & TCPOP & TJ & INF & ID & TX & TRADE & TC \\
\hline Brasil & $\mathrm{I}(0)$ & $\mathrm{I}(1)$ & $\mathrm{I}(0)$ & $\mathrm{I}(0)$ & $\mathrm{I}(0)$ & $\mathrm{I}(1)$ & $\mathrm{I}(0)$ & $\mathrm{I}(1)$ & $\mathrm{I}(0)$ \\
\hline China & $\mathrm{I}(0)$ & $\mathrm{I}(0)$ & $\mathrm{I}(1)$ & $\mathrm{I}(0)$ & $\mathrm{I}(0)$ & $\mathrm{I}(1)$ & $\mathrm{I}(0)$ & $\mathrm{I}(1)$ & $\mathrm{I}(0)$ \\
\hline Índia & $\mathrm{I}(0)$ & $\mathrm{I}(1)$ & $\mathrm{I}(0)$ & $\mathrm{I}(0)$ & $\mathrm{I}(0)$ & $\mathrm{I}(1)$ & $\mathrm{I}(1)$ & $\mathrm{I}(1)$ & $\mathrm{I}(0)$ \\
\hline África do Sul & $\mathrm{I}(0)$ & $\mathrm{I}(1)$ & $\mathrm{I}(0)$ & $\mathrm{I}(0)$ & $\mathrm{I}(0)$ & $\mathrm{I}(0)$ & $\mathrm{I}(0)$ & $\mathrm{I}(1)$ & $\mathrm{I}(0)$ \\
\hline Rússia & $\mathrm{I}(0)$ & $\mathrm{I}(0)$ & $\mathrm{I}(0)$ & $\mathrm{I}(0)$ & $\mathrm{I}(0)$ & $\mathrm{I}(0)$ & $\mathrm{I}(0)$ & $\mathrm{I}(0)$ & $\mathrm{I}(0)$ \\
\hline VAR & Modelo & Modelo & Modelo & & & & & & \\
(Defasagens) & 1 & 2 & 3 & & & & & & \\
\hline Brasil & VAR (3) & VAR (3) & VAR (3) & & & & & & \\
\hline China & VAR (3) & VAR (3) & VAR (3) & & & & & & \\
\hline Índia & VAR (3) & VAR (3) & VAR (3) & & & & & & \\
\hline África do Sul & VAR (3) & VAR (3) & VAR (1) & & & & & \\
\hline
\end{tabular}

A análise de decomposição de variância tem por objetivo avaliar a contribuição relativa das diversas variáveis para a taxa de crescimento (TCPIB). Os resultados para os cinco países encontram-se sistematizados nas tabelas 2 a $6 .^{16}$

A estimação da ADV para o Brasil (modelo 1) revela que a taxa de investimento é a variável mais importante, com 44,5\%, e a inflação tem também

(15) Os resultados dos t-ADF para os quatro países (Brasil, China, Índia e África do Sul) e as nove variáveis utilizadas podem ser solicitados aos autores, assim como o valor do critério de Schwarz de escolha das defasagens dos três modelos VAR para tais países.

(16) Cabe ressaltar que foram apresentados apenas os resultados da ADV para TCPIB, dado que este é o objetivo da investigação empírica proposta no trabalho. 
uma importância significativa, com $11,4 \%$, para explicar o crescimento. O modelo 2 indica a predominância de TXI $(35,9 \%)$ na explicação da variância de TCPIB, mas pode-se destacar também o papel da taxa de juros real (28\%) e a mudança no câmbio real efetivo $(4,3 \%)$. No modelo 3 , a variação nos fluxos de capitais (IDE) tem a maior relevância, com $12,6 \%$. O crescimento populacional $(8,2 \%)$ e a inflação (7\%) também desempenham papel importante. A análise do caso brasileiro revela que a taxa de investimento é a variável mais importante para o crescimento nos dois modelos onde esteve presente. A variável inflação também foi destaque em dois modelos como a segunda variável de maior relevância. Com isso, pode-se dizer que, para o Brasil, políticas que tenham impacto em termos de elevação da taxa de investimento, bem como a manutenção da estabilidade inflacionária, são fundamentais para se elevar a taxa de crescimento.

Tabela 2

ADV para TCPIB - Brasil - Modelos 1, 2 e 3 (1980 A 2005) - VAR (3)

\begin{tabular}{l|r|r|r|r|r}
\hline $\begin{array}{l}\text { Modelo } 1 \\
\text { Período }\end{array}$ & \multicolumn{1}{|c|}{ TCPIB } & \multicolumn{1}{|c|}{ TXI } & INF & TCPOP & DTRADE \\
\hline 1 & 100,000 & 0,000 & 0,000 & 0,000 & 0,000 \\
\hline 5 & 46,774 & 44,142 & 6,968 & 1,217 & 0,896 \\
\hline 10 & 40,705 & 44,537 & 11,437 & 1,555 & 1,763 \\
\hline
\end{tabular}

Ordem de Cholesky: TCPIB TXI INF TCPOP DTRADE

\begin{tabular}{l|c|c|c|c|c}
\hline $\begin{array}{l}\text { Modelo } 2 \\
\text { Período }\end{array}$ & TCPIB & TXI & TJREAL & DTCREF & DTRADE \\
\hline 1 & 100,000 & 0,000 & 0,000 & 0,000 & 0,000 \\
\hline 5 & 39,853 & 46,203 & 10,183 & 3,553 & 0,205 \\
\hline 10 & 31,056 & 35,939 & 28,029 & 4,3687 & 0,604 \\
\hline \multicolumn{5}{l}{ Ordem de Cholesky: TCPIB TXI TJREAL DTCREF DTRADE } \\
\hline $\begin{array}{l}\text { Modelo 3 } \\
\text { Período }\end{array}$ & TCPIB & INF & TCPOP & DIDE & TCX \\
\hline 1 & 100,000 & 0,000 & 0,000 & 0,000 & 0,000 \\
\hline 5 & 87,158 & 2,414 & 6,202 & 1,905 & 2,319 \\
\hline 10 & 69,105 & 7,004 & 8,215 & 12,683 & 2,990 \\
\hline
\end{tabular}

Os resultados da ADV para a China, utilizando o modelo 1, revelam a predominância da inflação $(20,9 \%)$ na explicação da variância do crescimento, participações iguais para a taxa de investimento $(2,6 \%)$ e a mudança no grau de abertura (2,6\%). A importância da taxa de investimento no modelo 2 é bastante distinta e se destaca com 55,8\%, seguida pela taxa de câmbio real efetiva $(4,8 \%)$ e a taxa de juros real (4,3\%). Analisando o modelo 3, percebe-se, assim como no modelo 1 , a relevância da inflação $(14,9 \%)$, da mudança na taxa de crescimento populacional $(4,3 \%)$ e dos fluxos de IDE $(3,7 \%)$ na explicação do crescimento. $\mathrm{O}$ que pode ser apreendido dos resultados da ADV para a China é que a estabilidade inflacionária é uma variável crucial para o crescimento, porém outras variáveis 
como a taxa de investimento, o câmbio real efetivo, os fluxos de IDE e o crescimento populacional têm um papel importante na explicação do crescimento chinês.

Tabela 3

ADV para TCPIB - China - Modelos 1, 2 e 3 (1980 A 2005) - VAR (3)

\begin{tabular}{c|c|c|c|c|c}
\hline $\begin{array}{c}\text { Modelo 1 } \\
\text { Período }\end{array}$ & TCPIB & TXI & INF & DTCPOP & DTRADE \\
\hline 1 & 100,000 & 0,000 & 0,000 & 0,0000 & 0,000 \\
\hline 5 & 71,116 & 0,930 & 24,228 & 1,1389 & 2,585 \\
\hline 10 & 72,249 & 2,699 & 20,970 & 1,3994 & 2,680 \\
\hline
\end{tabular}

Ordem de Cholesky: TCPIB TXI INF DTCPOP DTRADE

\begin{tabular}{c|c|c|c|c|c}
\hline $\begin{array}{l}\text { Modelo } 2 \\
\text { Período }\end{array}$ & TCPIB & TXI & TJREAL & TCREF & DTRADE \\
\hline 1 & 100,000 & 0,000 & 0,000 & 0,000 & 0,000 \\
\hline 5 & 32,051 & 60,501 & 3,609 & 2,539 & 1,298 \\
\hline 10 & 33,635 & 55,840 & 4,391 & 4,801 & 1,330 \\
\hline \multicolumn{7}{l}{ Ordem de Cholesky: TCPIB TXI TJREAL TCREF DTRADE } \\
\hline
\end{tabular}

\begin{tabular}{c|c|c|c|c|c}
\hline $\begin{array}{l}\text { Modelo 3 } \\
\text { Período }\end{array}$ & TCPIB & INF & DIDE & DTCPOP & TCX \\
\hline 1 & 100,000 & 0,000 & 0,000 & 0,000 & 0,000 \\
\hline 5 & 81,872 & 11,474 & 2,924 & 3,555 & 0,172 \\
\hline 10 & 76,725 & 14,934 & 3,736 & 4,310 & 0,292 \\
\hline \multicolumn{7}{l}{ Ordem de Cholesky: TCPIB INF DIDE DTCPOP TCX } \\
\hline
\end{tabular}

Tabela 4

ADV para TCPIB - Índia - Modelos 1, 2 e 3 (1980 A 2005) - VAR (3)

\begin{tabular}{c|c|c|c|c|c}
\hline $\begin{array}{c}\text { Modelo } 1 \\
\text { Período }\end{array}$ & TCPIB & DTXI & INF & TCPOP & DTRADE \\
\hline 1 & 100,000 & 0,000 & 0,000 & 0,000 & 0,000 \\
\hline 5 & 48,760 & 19,508 & 24,735 & 5,920 & 1,076 \\
\hline 10 & 48.344 & 14,983 & 29,665 & 5,907 & 1,099 \\
\hline
\end{tabular}

Ordem de Cholesky: TCPIB DTXI INF TCPOP DTRADE

\begin{tabular}{c|c|c|c|c|c}
\hline $\begin{array}{l}\text { Modelo } 2 \\
\text { Período }\end{array}$ & TCPIB & DTXI & TJREAL & DTCREAL & DTRADE \\
\hline 1 & 100,000 & 0,000 & 0,000 & 0,000 & 0,000 \\
\hline 5 & 38,805 & 36,821 & 20,838 & 2,856 & 0,678 \\
\hline 10 & 34,396 & 21,699 & 21,082 & 13,918 & 8,901 \\
\hline
\end{tabular}

Ordem de Cholesky: TCPIB DTXI TJREAL DTCREAL DTRADE

\begin{tabular}{c|c|c|c|c|c}
\hline $\begin{array}{l}\text { Modelo 3 } \\
\text { Período }\end{array}$ & TCPIB & INF & DIDE & TCPOP & TCX \\
\hline 1 & 100,000 & 0,000 & 0,000 & 0,000 & 0,000 \\
\hline 5 & 65,584 & 12,157 & 7,581 & 13,510 & 1,165 \\
\hline 10 & 45,813 & 36,555 & 8,735 & 7,840 & 1,053 \\
\hline
\end{tabular}

Ordem de Cholesky: TCPIB INF DIDE TCPOP TCX 
A análise da ADV para o crescimento na Índia revela que, no modelo 1, a inflação $(29,6 \%)$ e a mudança na taxa de investimento $(14,9 \%)$ foram as variáveis mais relevantes, sendo que a taxa de crescimento populacional $(5,9 \%)$ tem uma contribuição secundária, embora importante. No modelo 2 , o destaque cabe, de maneira igualitária, às variáveis taxa de investimento $(21,6 \%)$ e taxa de juros real $(21 \%)$, mas a mudança na taxa de câmbio real $(13,9 \%)$ e no grau de abertura $(8,9 \%)$ também são relevantes na explicação do crescimento indiano. Quanto ao modelo 3, há uma predominância da contribuição da inflação $(36,5 \%)$ na explicação do crescimento, seguida pela mudança nos fluxos de IDE $(8,7 \%)$ e na taxa de crescimento populacional (7,8\%). De forma geral, o crescimento da Índia parece estar primordialmente associado à inflação, à taxa de investimento e à taxa de juros real, embora o câmbio real e o crescimento populacional exerçam um papel importante.

A estimação da ADV do crescimento na África do Sul revela que, no modelo 1 , a taxa de investimento $(33,7 \%)$ e a inflação $(18,7 \%)$ são as variáveis mais importantes, seguidas da taxa de crescimento populacional $(9,8 \%)$. Para o modelo 2 , a taxa de juros real $(13,2 \%)$ e a taxa de investimento $(12,2 \%)$ têm a maior contribuição relativa, enquanto a mudança no grau de abertura $(7,4 \%)$ também se mostrou relevante. Os resultados do modelo 3 destacam a participação dos fluxos de IDE (12\%) e da inflação (11,7\%), e de contribuições similares para as taxas de crescimento populacional e das exportações, ambas com 4,6\%. Em termos gerais, o crescimento na África do Sul está associado essencialmente a quatro fatores - taxa de investimento e inflação, em um primeiro plano, além dos fluxos de IDE e da taxa de juros real.

Tabela 5

ADV para TCPIB - África do Sul - Modelos 1 e 2 - VAR (3) e Modelo 3 - VAR (1) (1980 A 2005)

\begin{tabular}{c|c|c|c|c|c}
\hline $\begin{array}{l}\text { Modelo } 1 \\
\text { Período }\end{array}$ & TCPIB & TXI & INF & TCPOP & DTRADE \\
\hline 1 & 100,000 & 0,000 & 0,000 & 0,000 & 0,000 \\
\hline 5 & 57,264 & 16,412 & 21,171 & 4,406 & 0,744 \\
\hline 10 & 36,953 & 33,727 & 18,731 & 9,843 & 0,7433 \\
\hline \multicolumn{2}{l}{ Ordem de Cholesky: TCPIB TXI INF TCPOP DTRADE } \\
\hline
\end{tabular}

Ordem de Cholesky: TCPIB TXI INF TCPOP DTRADE

\begin{tabular}{l|c|c|c|c|c}
\hline $\begin{array}{l}\text { Modelo } 2 \\
\text { Período }\end{array}$ & TCPIB & TXI & TJREAL & DTCREF & DTRADE \\
\hline 1 & 100,000 & 0,000 & 0,000 & 0,000 & 0,000 \\
\hline 5 & 67,305 & 13,500 & 12,019 & 2,275 & 4,899 \\
\hline 10 & 64,379 & 12,230 & 13,221 & 2,734 & 7,433 \\
\hline \multicolumn{7}{l}{ Ordem de Cholesky: TCPIB TXI TJREAL DTCREF DTRADE } \\
\hline $\begin{array}{c}\text { Modelo 3 } \\
\text { Período }\end{array}$ & TCPIB & INF & IDE & TCPOP & TCX \\
\hline 1 & 100,000 & 0,000 & 0,000 & 0,000 & 0,000 \\
\hline 5 & 79,905 & 9,217 & 4,019 & 1,329 & 5,528 \\
\hline 10 & 66,939 & 11,742 & 12,001 & 4,683 & 4,632 \\
\hline
\end{tabular}


Tabela 6

ADV para TCPIB - Rússia - Modelos 1, 2 e 3 (1993 A 2005) - VAR (1)

\begin{tabular}{l|c|c|c|c|c}
\hline $\begin{array}{c}\text { Modelo } 1 \\
\text { Período }\end{array}$ & TCPIB & TXI & INF & TCPOP & TRADE \\
\hline 1 & 100,000 & 0,000 & 0,000 & 0,000 & 0,000 \\
\hline 5 & 24,864 & 30,588 & 39,265 & 4,925 & 0,356 \\
\hline 10 & 24,630 & 29,724 & 40,383 & 4,897 & 0,364 \\
\hline \multicolumn{7}{|l|}{ Ordem de Cholesky: TCPIB TXI INF TCPOP TRADE } \\
\hline $\begin{array}{c}\text { Modelo 2 } \\
\text { Período }\end{array}$ & TCPIB & TXI & TJREAL & TCREF & TRADE \\
\hline 1 & 100,000 & 0,000 & 0,000 & 0,000 & 0,000 \\
\hline 5 & 89,247 & 4,544 & 4,581 & 0,950 & 0,675 \\
\hline 10 & 88,494 & 4,366 & 5,049 & 1,227 & 0,861 \\
\hline \multicolumn{7}{|l}{ Ordem de Cholesky: TCPIB TXI TJREAL TCREF TRADE } \\
\hline
\end{tabular}

\begin{tabular}{c|c|c|c|c|c}
\hline $\begin{array}{c}\text { Modelo 3 } \\
\text { Período }\end{array}$ & TCPIB & INF & IDE & TCPOP & TCX \\
\hline 1 & 100,000 & 0,000 & 0,000 & 0,000 & 0,000 \\
\hline 5 & 76,038 & 2,113 & 4,452 & 15,903 & 1,490 \\
\hline 10 & 76,031 & 2,110 & 4,456 & 15,907 & 1,494 \\
\hline
\end{tabular}

Ordem de Cholesky: TCPIB INF IDE TCPOP TCX

Os resultados da ADV do crescimento na Rússia, feitas as ressalvas para o período limitado de análise (1993 a 2005) quando comparado às demais estimações para os demais países (1980 a 2005), revelam que, no modelo 1, a inflação $(40,3 \%)$ e a taxa de investimento $(29,7 \%)$ são responsáveis por boa parte da explicação da variância do crescimento. No modelo 2 , o conjunto das variáveis foi responsável pela explicação de apenas $11,6 \%$ da variância do crescimento e, nesse sentido, é um modelo com menor grau de ajuste, sendo que as contribuições da taxa de juros real (5\%) e da taxa de investimento $(4,3 \%)$ tiveram alguma relevância. Quanto ao modelo 3, a maior contribuição está associada à taxa de crescimento populacional $(15,9 \%)$ e aos fluxos de IDE $(4,4 \%)$. Em termos gerais, pode-se argumentar que o crescimento na Rússia é essencialmente explicado pela inflação e pela taxa de investimento e, de maneira secundária, pela taxa de crescimento populacional.

\section{Considerações finais}

A análise da literatura e dos dados comparativos para Brasil, Rússia, Índia, China (BRIC) e África do Sul desenvolvidas pelo trabalho possibilitam assimilar algumas lições importantes sobre o desempenho dessas economias em termos de taxa de crescimento do PIB. Uma dessas lições aponta para a importância de se elevar a taxa de investimento a médio e longo prazo para se obter taxas de crescimento mais elevadas e sustentadas ao longo do tempo. Outra lição diz respeito à importância dos fluxos de capitais externos como fonte de recursos 
adicionais necessários para se elevar a taxa de poupança e investimento da economia, além da relevância de se ter uma maior participação no comércio internacional através da ampliação no grau de abertura e da participação das exportações no PIB.

As lições acima listadas são fruto de uma leitura geral comparativa entre as economias do BRIC e África do Sul, porém não se pode esquecer as especificidades de cada uma em teremos dos distintos aspectos macro e microeconômicos, e em termos de suas histórias distintas, como é o caso dos regimes políticos e econômicos da China e da Rússia, onde sistemas não capitalistas foram adotados durante um longo período de tempo.

Os resultados econométricos da análise de decomposição de variância para as cinco economias revelaram uma predominância do papel da taxa de investimento e da inflação para o crescimento econômico, ainda que outros fatores tenham sido importantes em menor magnitude.

A análise da ADV para o Brasil indica que a taxa de investimento é a variável mais importante para o crescimento nos dois modelos onde esteve presente, sendo que a variável inflação também foi destaque em dois modelos como a segunda variável de maior relevância. Com isso, pode-se dizer que, para o Brasil, políticas que tenham impacto em termos de elevação da taxa de investimento, bem como a manutenção da estabilidade inflacionária, e mesmo em termos de redução da taxa de juros real, são fundamentais para se elevar a taxa de crescimento. Os resultados para a China revelam que a taxa de inflação é uma variável crucial para o crescimento, porém outras variáveis como a taxa de investimento, o câmbio real efetivo, os fluxos de IDE e o crescimento populacional têm um papel importante na explicação do crescimento chinês. Para a Índia, o crescimento parece estar primordialmente associado à inflação, à taxa de investimento e à taxa de juros real, embora o câmbio real e o crescimento populacional tenham também um papel importante. Na análise para a África do Sul, o crescimento está associado essencialmente a quatro fatores: a taxa de investimento e a inflação em um primeiro plano, além dos fluxos de IDE e da taxa de juros real. Finalmente, os resultados para a Rússia sugerem que o crescimento é explicado principalmente pela inflação e pela taxa de investimento e, de maneira secundária, pela taxa de crescimento populacional.

A análise teórica e empírica desenvolvida nesse trabalho sobre os determinantes do crescimento nos países do BRIC e África do Sul revela uma diversidade de fatores na explicação do desempenho desses países. Especificidades essas que estão associadas não apenas às características políticas e econômicas de cada um, mas que também têm se alterado ao longo do tempo, conferindo uma dinâmica própria ao crescimento. A tentativa aqui desenvolvida 
não é a de unificar as lições para o crescimento dos países do BRIC e África do Sul, mas buscar elos nessa explicação, de forma que os formuladores de política econômica possam incorporar tais elementos como subsídios valiosos para a definição futura de estratégias de crescimento sustentável nestas economias.

\section{Referências bibliográficas}

ACEMOGLU, D.; JOHNSON, S.; ROBINSON, J. A. Institutions as the fundamental cause of long-run growth. In: AGHION, Philippe; DURLAUF, Stephen (Ed.). Handbook of economic growth. North Holland: North Holland, Dec. 2005.

AIZERMAN, J. Financial liberalization in Latin-America in the 1990s: a reassessment. Feb. 2005. (NBER Working Paper, n. 11145)

ANDRADE, D. C. Fatores condicionantes do crescimento econômico de longo prazo na China: aspectos teóricos e investigação empírica. Dissertação (Mestrado)-IE-UFU, Uberlândia, MG, fev. 2006.

BANERJEE, A.; GALIANI, S.; LEVINSOHN, J.; MCLAREN, Z.; WOOLARD, I. Why has unemployment risen in the New South Africa. May 2007. (NBER Working Paper Series, n. 13167).

BARRO, R. J. Economic growth in East Asia before and after the financial crisis. Jun. 2001. (NBER Working Paper, n. 8330).

Inflation and economic growth. Oct. 1995. (NBER Working Paper, n. 5326).

Economic growth in a cross section of countries. The Quarterly Journal of Economics, n. 425, p. 407-443, May 1991.

; LEE, J. International data on educational attainment: updates and implications. Center for International Development, CID, Apr. 2000. (Working Paper, n. 42).

1995.

; SALA-I-MARTIN, X. Economic growth. Cambridge, Mass.: The MIT Press,

BERENGAUT, J.; ELBORGH-WOYTEK, K. Who is still haunted by the specter of communism? Explaining relative output contractions under transition. Apr. 2005. (IMF Working Paper, n. 05/68).

BOSWORTH, B.; COLLINS, S. M.; VIRMANI, A. Sources of growth in the Indian economy. Feb. 2007. (NBER Working Paper, n. 12901).

BRUNO, M.; EASTERLY, W. Inflation crises and long-run growth. Aug. 1995. (NBER Working Paper Series, n. 5209).

CALDERON, C.; FAJNZYLBER, P.; LOAYZA, N. V. Economic growth in Latin America and the Caribbean. The World Bank, Apr. 2005.

CARNEIRO, R. Desenvolvimento em crise: a economia brasileira no último quarto do século XX. São Paulo: Editora Unesp/IE. Unicamp, 2002.

CASS, D. Optimum growth in an aggregative model of capital accumulation. Review of Economic Studies, n. 32, p. 233-240, Jul. 1965. 
CHANG, R.; KALTANI, L.; LOAYZA, N. Openness can be good for growth: the role of policy complementarities. Nov. 2005. (NBER Working Paper, n. 11787).

DELONG, J. B. India since independence. An analytic growth narrative. In: RODRIK, D. In search of prosperity: analytic narratives of economic growth. Princeton, NJ: Princeton University Press, 2003.

DE PAULA, L. F. R.; FERRARI FILHO, F. Liberalização financeira e performance econômica: a experiência recente dos BRIC. In: ENCONTRO NACIONAL DE ECONOMIA POLÍTICA, 11, 2006, Vitória. Anais... São Paulo: Sociedade Brasileira de Economia Política (SEP), 2006.

DUBAS, J. M.; LEE, B. J.; MARK, N. C. Effective exchange rate classifications and growth. Apr. 2005. (NBER Working Paper, n. 11272).

EDWARDS, L.; LAWRENCE, R. Z. South African trade policy matters: trade performance and trade policy. Nov. 2006. (NBER Working Paper Series, n. 12760).

FOGEL, R. W. Why China is likely to achieve its growth objectives. Mar. 2006. NBER (Working Paper No.12122).

FRANKEL, J. On the rand: determinants of the South African exchange rate. Mar. 2007. (NBER Working Paper Series, n. 13050).

On the Renmimbi: the choice between adjustment under a fixed exchange rate and adjustment under a flexible rate. Apr. 2005. (NBER Working Paper, n. 11274).

HECKMAN, J. J. China's human capital investment. China Economic Review, v.16, p. 50-70, 2005.

IMF - INTERNATIONAL MONETARY FUND. Russian Federation: staff report for the 2007 Article IV Consultation. Oct. 2007. (IMF Country Report, n. 351).

International Financial Statistics - IFS, Feb. 2006.

KNIGHT, M.; LOAYZA, N. V.; VILLANUEVA, D. Testing the neoclassical theory of economic growth: a panel data approach. International Monetary Fund Staff Papers. v. 40, n. 3, p. 512-541, Sept. 1993.

KOCHHAR, K.; KUMAR, U.; RAJAN, R.; SUBRAMANIAN, A.; TOKATLIDIS, I. India's pattern of development: what happened, what follows. Feb. 2006. (NBER Working Paper Series, n. 12023).

KOOPMANS, T. On the concept of optimal economic growth. In: THE ECONOMETRIC Approach to Development Planning. Pontificia Acad. Sc. Scripta Varia 28, p. 225-300, North-Holland, 1966.

LAI, P. China's foreign trade: achievements, determinants and future policy challenges. China \& World Economy, v. 12, n. 6, p. 38-50, 2004.

LEE, J. W.; BARRO, R. J. Schooling quality in a cross-section of countries. Economica, v. 68 , n. 271, p. 465-488, Nov. 2001.

LUCAS JR., R. E. On the mechanics of economic development. Journal of Monetary Economics, n. 22, p. 3-42, Jul. 1988. 
NASSIF, A. A economia indiana no período 1950-2004 - Da estagnação ao crescimento acelerado: lições para o Brasil? Rio de Janeiro: BNDES, jan. 2006. (Texto para Discussão, n. 107).

OWEN, D.; ROBINSON, D. O. Russia rebounds. International Monetary Fund. Sept., 2003.

RAMSEY, F. A mathematical theory of saving. Economic Journal, v. 38, p. 543-559, Dec. 1928.

REBELO, S. Long-run policy analysis and long-run growth. Journal of Political Economy, v. 99, n. 3, p. 500-521, Jun. 1991.

RODRIK, D. What is so special about China's exports? Jan. 2006a. (NBER Working Paper Series, n. 11947).

Understanding South Africa's economic puzzles. London: Centre for Economic Policy Research, 2006b. (CEPR Discussion Paper, n. 5907).

; SUBRAMANIAN, A. From "Hindu Growth" to productivity surge: the mystery of the Indian growth transition. Mar. 2004. (NBER Working Paper, n.10376).

ROMER, P. M. Advanced macroeconomics. New York: McGraw-Hill, 1996.

Increasing returns and long-run growth. Journal of Political Economy, v. 94, n. 5, p.1002-1037, Oct. 1986.

SICSÚ, J. Rumos e definições da política econômica brasileira: do plano A de FHC para o plano A+ de Lula. In: SICSÚ, J. Emprego, juros e câmbio - Finanças globais e desemprego. Rio de Janeiro: Elsevier, 2007. Cap. 14.

SOLOW, R. M. A contribution to the theory of economic growth. Quarterly Journal of Economics, n. 70, p. 65-94, 1956.

TAYLOR, A. M. On the costs of inward-looking development: historical perspectives on price distortions, growth, and divergence in Latin American from 1930s-1980s. Journal of Economic History, v. 58, n. 1, p. 1-28, 1998.

VELASCO, S. Reformas econômicas na Índia: discurso e processo. Boletim Economia Política Internacional - Análise Estratégica, Centro de Estudos de Relações Econômicas Internacionais. Unicamp. Campinas, n. 7, out./dez. 2005.

WANG, Y.; YAO, Y. Sources of China's economic growth 1952-1999: incorporating human capital accumulation. China Economic Review, v. 14, p. 32-52, 2003.

WILSON, D.; PURUSHOTHAMAN, R. Dreaming with BRICs: the Path to 2050. Global Economics Paper, Goldman Sachs, n. 99, Oct. 2003.

WORLD BANK. From transition to development: a country economic memorandum for the Russian Federation. Moscou, 2005.

WORLD DEVELOPMENT INDICATORS - WDI. Banco de Dados do Banco Mundial. 2007. (CD ROOM).

WORLD ECONOMIC OUTLOOK - WEO. Fundo Monetário Internacional, FMI, Oct. 2007. 


\section{Apêndice}

Tabela $1 \mathrm{~A}$

Nomenclatura das variáveis

\begin{tabular}{l|l}
\hline TCPIB & Taxa de crescimento do PIB Real (em \%) \\
\hline TCPOP & Taxa de crescimento populacional $(\%)$ \\
\hline TAM & PIB Real país / PIB Real dos EUA \\
\hline INF & Taxa de inflação (\% a.a.) \\
\hline TCREF & Taxa de câmbio real efetiva $(2000=100)$ \\
\hline TCREAL & Taxa de câmbio Real $(2000=100)$ \\
\hline TC & Taxa de câmbio (Moeda Local / US\$) \\
\hline X & Exportações (\% do PIB) \\
\hline TCX & Taxa de crescimento das exportações $(\%)$ \\
\hline TJ & Taxa de Juros Real $(\%$ a.a.) \\
\hline TRADE & Exportações + Importações / PIB (\%) \\
\hline TXI & Formação bruta de capital fixo (\% do PIB) \\
\hline IDE & IDE = fluxos de IDE $(\%$ do PIB) \\
\hline DIVX & Dívida total $(\%$ das X) \\
\hline DIVC & Dívida de curto prazo $(\%$ das X) \\
\hline DIVL & Dívida de longo prazo $(\%$ das X) \\
\hline Fonte: WDI (2007); & WEO (2007); IFS (2006).
\end{tabular}


Tabela 2A

Brasil (1980 a 2005)

\begin{tabular}{|c|c|c|c|c|c|c|c|c|c|c|c|c|c|c|c|}
\hline Anos & TCPIB & TCPOP & TAM & INF & TCREF & $\mathrm{TC}$ & $\mathrm{X}$ & TCX & TJ & TRADE & TXI & IDE & DIVX & DIVC & DIVL \\
\hline 1980 & 9,200 & 2,338 & 0,046 & 132,600 & 99,739 & 0,000 & 9,053 & 22,614 & $-85,268$ & 20,359 & 22,902 & 0,813 & 63,252 & 58,032 & 41,968 \\
\hline 1981 & $-4,400$ & 2,328 & 0,049 & 101,700 & 85,601 & 0,000 & 9,420 & 21,320 & $-11,964$ & 19,220 & 22,937 & 0,956 & 66,220 & 56,878 & 43,122 \\
\hline 1982 & 0,600 & 2,310 & 0,052 & 100,500 & 77,400 & 0,000 & 7,610 & $-9,191$ & 20,160 & 15,884 & 21,436 & 1,033 & 81,755 & 74,388 & 25,612 \\
\hline 1983 & $-3,400$ & 2,269 & 0,035 & 135,000 & 99,179 & 0,000 & 11,422 & 14,332 & 68,231 & 20,430 & 18,130 & 0,791 & 54,616 & 58,550 & 41,450 \\
\hline 1984 & 5,300 & 2,202 & 0,033 & 192,100 & 107,915 & 0,000 & 13,548 & 21,955 & 65,220 & 21,472 & 16,886 & 0,763 & 45,347 & 36,442 & 63,558 \\
\hline 1985 & 7,900 & 2,117 & 0,035 & 226,000 & 112,422 & 0,000 & 12,248 & 7,027 & 55,654 & 19,343 & 16,948 & 0,646 & 39,104 & 31,978 & 68,022 \\
\hline 1986 & 7,500 & 2,030 & 0,041 & 147,100 & 114,235 & 0,000 & 8,817 & $-10,581$ & $-41,876$ & 15,171 & 19,093 & 0,129 & 46,196 & 37,494 & 62,506 \\
\hline 1987 & 3,600 & 1,949 & 0,044 & 228,300 & 109,342 & 0,000 & 9,460 & 19,235 & 196,076 & 15,653 & 22,305 & 0,398 & 41,595 & 46,512 & 53,488 \\
\hline 1988 & 0,300 & 1,868 & 0,045 & 629,100 & 107,263 & 0,000 & 10,888 & 13,079 & 563,770 & 16,581 & 22,718 & 0,849 & 45,727 & 28,479 & 71,521 \\
\hline 1989 & 3,200 & 1,788 & 0,060 & 1430,700 & 83,859 & 0,000 & 8,218 & 5,086 & 4974,270 & 13,244 & 24,758 & 0,245 & 36,314 & 46,303 & 53,697 \\
\hline 1990 & $-4,200$ & 1,712 & 0,066 & 2947,700 & 70,100 & 0,000 & 8,200 & $-4,922$ & 12830,900 & 15,162 & 20,660 & 0,214 & 22,175 & 64,352 & 35,648 \\
\hline 1991 & 1,000 & 1,635 & 0,057 & 477,400 & 81,759 & 0,000 & 8,677 & 6,577 & 370,138 & 16,591 & 18,109 & 0,271 & 22,603 & 71,312 & 28,688 \\
\hline 1992 & $-0,500$ & 1,566 & 0,053 & 1022,500 & 91,127 & 0,002 & 10,868 & 10,381 & 551,780 & 19,253 & 18,423 & 0,528 & 20,241 & 56,392 & 43,608 \\
\hline 1993 & 4,900 & 1,518 & 0,057 & 1927,400 & 85,730 & 0,032 & 10,503 & 10,190 & 1357,040 & 19,599 & 19,283 & 0,295 & 23,646 & 68,056 & 31,944 \\
\hline 1994 & 5,900 & 1,498 & 0,069 & 2075,800 & 80,732 & 0,639 & 9,513 & 7,673 & 2744,840 & 18,675 & 20,748 & 0,562 & 30,049 & 60,656 & 39,344 \\
\hline 1995 & 4,200 & 1,497 & 0,096 & 66,000 & 73,680 & 0,918 & 7,725 & $-1,442$ & $-12,628$ & 17,213 & 20,544 & 0,690 & 36,576 & 52,955 & 47,045 \\
\hline 1996 & 2,200 & 1,503 & 0,101 & 16,000 & 70,917 & 1,005 & 7,122 & 0,640 & & 16,300 & 19,115 & 1,445 & 42,224 & 60,157 & 39,843 \\
\hline 1997 & 3,400 & 1,504 & 0,100 & 6,900 & 70,926 & 1,078 & 7,521 & 11,150 & 18,103 & 17,661 & 19,493 & 2,433 & 62,662 & 52,933 & 47,067 \\
\hline 1998 & 0,000 & 1,499 & 0,093 & 3,200 & 72,263 & 1,161 & 7,314 & 3,710 & 26,301 & 17,250 & 19,602 & 4,051 & 79,452 & 46,244 & 53,756 \\
\hline 1999 & 0,300 & 1,484 & 0,062 & 4,900 & 106,062 & 1,815 & 10,282 & 9,250 & 21,361 & 22,107 & 19,087 & 5,325 & 117,883 & 48,455 & 51,545 \\
\hline 2000 & 4,300 & 1,462 & 0,066 & 7,100 & 99,999 & 1,830 & 10,663 & 10,590 & 10,488 & 22,838 & 21,813 & 5,447 & 93,653 & 44,684 & 55,316 \\
\hline 2001 & 1,300 & 1,439 & 0,056 & 6,800 & 118,668 & 2,358 & 13,222 & 11,240 & 10,667 & 27,438 & 20,597 & 4,417 & 75,962 & 39,267 & 60,733 \\
\hline 2002 & 2,700 & 1,417 & 0,050 & 8,400 & 125,410 & 2,921 & 15,489 & 7,900 & 10,713 & 28,903 & 18,980 & 3,600 & 70,047 & 31,227 & 68,773 \\
\hline 2003 & 1,100 & 1,395 & 0,054 & 14,800 & 124,981 & 3,077 & 16,375 & 8,950 & 8,567 & 29,147 & 16,366 & 2,006 & 66,426 & 27,669 & 72,331 \\
\hline 2004 & 5,700 & 1,371 & 0,062 & 6,600 & 123,753 & 2,925 & 18,022 & 17,990 & 9,644 & 31,377 & 18,211 & 3,008 & 46,692 & 22,026 & 77,974 \\
\hline 2005 & 2,900 & 1,346 & 0,080 & 6,900 & 105,373 & 2,434 & 16,773 & 11,620 & 12,223 & 29,163 & 18,326 & 1,909 & 44,805 & 17,128 & 82,872 \\
\hline $\begin{array}{l}\text { Média } 1980 \\
\text { a } 1992\end{array}$ & 2,008 & 2,009 & 0,047 & 597,746 & 0,000 & 95,380 & 9,879 & 8,993 & 17,566 & 1504,392 & 20,408 & 0,587 & 45,011 & 51,316 & 48,684 \\
\hline $\begin{array}{l}\text { Média } 1993 \\
\text { a } 2005\end{array}$ & 2,992 & 1,456 & 0,073 & 319,292 & 1,707 & 96,807 & 11,579 & 8,420 & 22,898 & 325,290 & 19,397 & 2,707 & 60,775 & 43,958 & 56,042 \\
\hline
\end{tabular}

Fonte: WDI (2007); WEO (2007); IFS (2006). 
Tabela 3A

China (1980 a 2005)

\begin{tabular}{|c|c|c|c|c|c|c|c|c|c|c|c|c|c|c|c|}
\hline Anos & TCPIB & TCPOP & TAM & INF & $\mathrm{TC}$ & TCREF & $X$ & TCX & TRADE & $\mathrm{TJ}$ & TXI & IDE & DIVX & DIVC & DIVL \\
\hline 1980 & 7,900 & 1,254 & 0,099 & 6,000 & 1,498 & 288,972 & 10,713 & 7,969 & 21,794 & 1,213 & 29,271 & 0,030 & & & \\
\hline 1981 & 4,700 & 1,281 & 0,089 & 2,400 & 1,705 & 258,348 & 12,651 & 16,638 & 24,792 & 2,671 & 27,544 & 0,137 & & & \\
\hline 1982 & 9,100 & 1,473 & 0,089 & 1,900 & 1,893 & 246,606 & 12,324 & 1,824 & 22,496 & 7,406 & 28,391 & 0,213 & 8,409 & 9,102 & 90,898 \\
\hline 1983 & 10,900 & 1,445 & 0,091 & 1,500 & 1,976 & 242,454 & 10,909 & $-0,671$ & 20,824 & 6,068 & 29,039 & 0,280 & 10,688 & 15,821 & 84,179 \\
\hline 1984 & 15,200 & 1,312 & 0,083 & 2,800 & 2,320 & 216,112 & 11,339 & 14,203 & 22,733 & 2,200 & 29,940 & 0,491 & 7,867 & 19,283 & 80,717 \\
\hline 1985 & 13,500 & 1,362 & 0,071 & 9,300 & 2,937 & 183,353 & 9,999 & 2,035 & 24,132 & $-2,016$ & 29,807 & 0,544 & 8,310 & 21,525 & 78,475 \\
\hline 1986 & 8,800 & 1,487 & 0,064 & 6,500 & 3,453 & 133,486 & 11,820 & 0,712 & 26,514 & 3,171 & 30,775 & 0,634 & 9,626 & 19,669 & 80,331 \\
\hline 1987 & 11,600 & 1,604 & 0,064 & 7,300 & 3,722 & 115,628 & 16,355 & 8,051 & 32,742 & 2,716 & 31,755 & 0,863 & 9,554 & 20,393 & 79,607 \\
\hline 1988 & 11,300 & 1,610 & 0,068 & 18,800 & 3,722 & 96,215 & 17,050 & 7,621 & 35,489 & $-2,785$ & 31,497 & 1,040 & 9,608 & 18,535 & 81,465 \\
\hline 1989 & 4,100 & 1,533 & 0,068 & 18,000 & 3,765 & 110,929 & 16,697 & 2,498 & 34,418 & 2,327 & 26,136 & 0,991 & 11,347 & 13,871 & 86,129 \\
\hline 1990 & 3,800 & 1,467 & 0,055 & 3,100 & 4,783 & 98,878 & 19,166 & 5,190 & 34,826 & 3,487 & 26,029 & 0,983 & 11,662 & 15,396 & 84,604 \\
\hline 1991 & 9,200 & 1,364 & 0,054 & 3,400 & 5,323 & 88,194 & 20,952 & 13,079 & 38,301 & 1,788 & 28,080 & 1,159 & 11,888 & 15,439 & 84,561 \\
\hline 1992 & 14,200 & 1,226 & 0,057 & 6,400 & 5,515 & 79,273 & 22,526 & 11,208 & 43,271 & 0,685 & 31,961 & 2,668 & 10,182 & 16,263 & 83,737 \\
\hline 1993 & 14,000 & 1,150 & 0,061 & 14,700 & 5,762 & 70,093 & 23,301 & 13,608 & 48,676 & $-4,619$ & 37,667 & 6,246 & 11,129 & 16,744 & 83,256 \\
\hline 1994 & 13,100 & 1,130 & 0,044 & 24,100 & 8,619 & 76,044 & 24,566 & 25,168 & 47,313 & $-7,982$ & 35,920 & 6,042 & 8,886 & 13,951 & 86,049 \\
\hline 1995 & 10,900 & 1,087 & 0,049 & 17,100 & 8,351 & 84,726 & 23,073 & 6,387 & 43,936 & $-1,474$ & 34,354 & 4,924 & 9,861 & 14,613 & 85,387 \\
\hline 1996 & 10,000 & 1,048 & 0,053 & 8,300 & 8,314 & 93,214 & 20,054 & $-0,706$ & 38,057 & 3,424 & 33,786 & 4,693 & 8,721 & 14,063 & 85,937 \\
\hline 1997 & 9,300 & 1,023 & 0,055 & 2,800 & 8,290 & 100,363 & 21,754 & 22,926 & 39,013 & 7,021 & 32,878 & 4,644 & 8,485 & 14,475 & 85,525 \\
\hline 1998 & 7,800 & 0,960 & 0,057 & $-0,800$ & 8,279 & 105,692 & 20,347 & 7,163 & 36,393 & 7,311 & 33,849 & 4,292 & 8,645 & 8,131 & 91,869 \\
\hline 1999 & 7,600 & 0,946 & 0,059 & $-1,400$ & 8,278 & 99,964 & 20,398 & 15,164 & 37,967 & 7,195 & 34,041 & 3,577 & 11,696 & 6,609 & 93,391 \\
\hline 2000 & 8,400 & 0,708 & 0,062 & 0,400 & 8,279 & 100,000 & 23,326 & 30,566 & 44,243 & 3,711 & 34,112 & 3,204 & 9,257 & 4,469 & 95,531 \\
\hline 2001 & 8,300 & 0,726 & 0,066 & 0,700 & 8,277 & 104,301 & 22,600 & 9,621 & 43,081 & 3,721 & 34,430 & 3,339 & 7,923 & 18,178 & 81,822 \\
\hline 2002 & 9,100 & 0,670 & 0,071 & $-0,800$ & 8,277 & 101,887 & 25,133 & 29,415 & 47,695 & 4,698 & 36,259 & 3,392 & 8,280 & 17,495 & 82,505 \\
\hline 2003 & 10,000 & 0,623 & 0,076 & 1,200 & 8,277 & 95,203 & 29,556 & 26,775 & 56,913 & 2,630 & 39,383 & 2,869 & 7,333 & 17,464 & 82,536 \\
\hline 2004 & 10,100 & 0,600 & 0,081 & 3,900 & 8,277 & 92,696 & 33,951 & 28,415 & 65,350 & $-1,246$ & 40,730 & 2,844 & 3,415 & 17,000 & 83,000 \\
\hline 2005 & 10,400 & 0,642 & 0,088 & 1,800 & 8,194 & 92,483 & 37,456 & 24,253 & 69,327 & 1,601 & 42,311 & 3,541 & 3,104 & 16,823 & 83,177 \\
\hline $\begin{array}{l}\text { Média } 1980 \\
\text { a } 1992\end{array}$ & 9,562 & 1,417 & 0,073 & 6,723 & 3,278 & 166,034 & 14,808 & 6,950 & 29,410 & 2,225 & 29,248 & 0,772 & 9,922 & 16,845 & 83,155 \\
\hline $\begin{array}{l}\text { Média } 1993 \\
\text { a } 2005\end{array}$ & 9,923 & 0,870 & 0,063 & 5,538 & 8,113 & 93,590 & 25,040 & 18,366 & 47,536 & 1,999 & 36,132 & 4,124 & 8,210 & 13,847 & 86,153 \\
\hline
\end{tabular}

Fonte: WDI (2007); WEO (2007); IFS (2006). 
Tabela 4A

Índia (1980 a 2005)

\begin{tabular}{|c|c|c|c|c|c|c|c|c|c|c|c|c|c|c|c|}
\hline Anos & TCPIB & TCPOP & TAM & INF & $\mathrm{TC}$ & TCREAL & X & TCX & TRADE & TJ & TXI & IDE & DIVX & DIVC & DIVL \\
\hline 1980 & 3,600 & 2,253 & 0,165 & 11,400 & 7,863 & 46,319 & 6,281 & 11,004 & 15,738 & 4,477 & 18,515 & 0,044 & 9,450 & 8,424 & 91,576 \\
\hline 1981 & 6,400 & 2,229 & 0,155 & 13,100 & 8,659 & 49,747 & 6,083 & $-0,689$ & 14,867 & 5,656 & 18,939 & 0,049 & 10,931 & 11,009 & 88,991 \\
\hline 1982 & 4,300 & 2,196 & 0,151 & 7,900 & 9,455 & 53,453 & 6,142 & 5,995 & 14,501 & 8,148 & 19,249 & 0,037 & 13,349 & 15,583 & 84,417 \\
\hline 1983 & 6,200 & 2,154 & 0,144 & 11,900 & 10,099 & 52,674 & 5,986 & $-0,667$ & 14,039 & 6,995 & 18,847 & 0,003 & 16,165 & 20,608 & 79,392 \\
\hline 1984 & 4,800 & 2,104 & 0,125 & 8,300 & 11,363 & 57,077 & 6,454 & 7,250 & 14,390 & 8,449 & 19,605 & 0,009 & 18,347 & 22,663 & 77,337 \\
\hline 1985 & 5,300 & 2,043 & 0,116 & 5,600 & 12,369 & 60,958 & 5,378 & $-6,202$ & 13,204 & 8,682 & 20,616 & 0,047 & 22,287 & 27,505 & 72,495 \\
\hline 1986 & 5,000 & 2,165 & 0,116 & 8,700 & 12,611 & 58,222 & 5,316 & 5,345 & 12,502 & 9,110 & 21,062 & 0,048 & 32,488 & 30,473 & 69,527 \\
\hline 1987 & 4,400 & 2,124 & 0,114 & 8,800 & 12,962 & 57,058 & 5,724 & 12,558 & 12,852 & 6,675 & 21,451 & 0,078 & 30,971 & 30,900 & 69,100 \\
\hline 1988 & 8,500 & 2,095 & 0,110 & 9,400 & 13,917 & 58,256 & 6,147 & 7,519 & 13,740 & 7,577 & 21,648 & 0,031 & 29,670 & 31,732 & 68,268 \\
\hline 1989 & 7,200 & 2,056 & 0,098 & 6,200 & 16,226 & 67,062 & 7,119 & 12,121 & 15,390 & 7,525 & 22,395 & 0,086 & 29,830 & 32,174 & 67,826 \\
\hline 1990 & 5,600 & 2,019 & 0,094 & 9,000 & 17,504 & 69,975 & 7,146 & 11,028 & 15,709 & 5,385 & 22,931 & 0,075 & 31,856 & 33,246 & 66,754 \\
\hline 1991 & 2,100 & 1,983 & 0,074 & 13,900 & 22,742 & 83,223 & 8,613 & 9,590 & 17,226 & 3,565 & 22,027 & 0,028 & 29,633 & 26,652 & 73,348 \\
\hline 1992 & 4,200 & 1,863 & 0,066 & 11,800 & 25,918 & 87,406 & 8,995 & 4,895 & 18,749 & 9,252 & 22,445 & 0,113 & 27,273 & 22,465 & 77,535 \\
\hline 1993 & 5,000 & 1,853 & 0,057 & 6,400 & 30,493 & 99,544 & 10,026 & 13,782 & 20,035 & 6,183 & 21,449 & 0,201 & 26,923 & 11,699 & 88,301 \\
\hline 1994 & 6,800 & 1,804 & 0,057 & 10,200 & 31,374 & 95,355 & 10,033 & 13,058 & 20,372 & 4,618 & 21,943 & 0,302 & 28,694 & 11,173 & 88,827 \\
\hline 1995 & 7,600 & 1,784 & 0,058 & 10,200 & 32,427 & 91,918 & 11,004 & 31,428 & 23,206 & 5,953 & 24,361 & 0,604 & 29,725 & 11,063 & 88,937 \\
\hline 1996 & 7,500 & 1,763 & 0,055 & 9,000 & 35,433 & 94,873 & 10,587 & 6,300 & 22,356 & 8,132 & 22,793 & 0,629 & 23,565 & 13,230 & 86,770 \\
\hline 1997 & 4,900 & 1,742 & 0,054 & 7,200 & 36,313 & 92,851 & 10,850 & $-2,341$ & 22,957 & 6,875 & 21,702 & 0,873 & 21,934 & 8,916 & 91,084 \\
\hline 1998 & 5,900 & 1,721 & 0,048 & 13,200 & 41,259 & 94,610 & 11,217 & 13,896 & 24,126 & 5,241 & 21,501 & 0,637 & 21,191 & 7,591 & 92,409 \\
\hline 1999 & 6,900 & 1,699 & 0,047 & 4,700 & 43,055 & 96,386 & 11,665 & 17,989 & 25,276 & 7,529 & 23,382 & 0,481 & 15,716 & 6,116 & 93,884 \\
\hline 2000 & 5,400 & 1,678 & 0,046 & 4,000 & 44,942 & 100,000 & 13,803 & $-7,240$ & 28,362 & 8,472 & 22,751 & 0,779 & 14,452 & 4,604 & 95,396 \\
\hline 2001 & 3,900 & 1,616 & 0,045 & 3,800 & 47,186 & 104,129 & 13,484 & 5,607 & 27,591 & 8,684 & 23,035 & 1,144 & 14,686 & 3,436 & 96,564 \\
\hline 2002 & 4,500 & 1,554 & 0,045 & 4,300 & 48,610 & 104,387 & 15,291 & 21,892 & 30,965 & 7,727 & 23,773 & 1,108 & 17,320 & 4,575 & 95,425 \\
\hline 2003 & 6,900 & 1,492 & 0,049 & 3,800 & 46,583 & 98,553 & 15,479 & 9,788 & 31,552 & 7,383 & 24,847 & 0,762 & 19,101 & 4,662 & 95,338 \\
\hline 2004 & 7,900 & 1,429 & 0,052 & 3,800 & 45,316 & 94,866 & 18,421 & 18,187 & 40,065 & 6,274 & 26,316 & 0,787 & & & \\
\hline 2005 & 9,000 & 1,367 & 0,057 & 4,200 & 44,100 & 91,571 & 20,539 & 21,853 & 44,716 & 6,033 & 28,055 & 0,819 & & & \\
\hline $\begin{array}{l}\text { Média } 1980 \\
\text { a } 1992\end{array}$ & 5,200 & 2,099 & 0,118 & 9,692 & 13,976 & 61,649 & 6,568 & 6,134 & 14,839 & 7,038 & 20,748 & 0,050 & 23,250 & 24,110 & 75,890 \\
\hline $\begin{array}{l}\text { Média } 1993 \\
\text { a } 2005\end{array}$ & 6,323 & 1,654 & 0,052 & 6,523 & 40,546 & 96,849 & 13,261 & 12,631 & 27,814 & 6,854 & 23,531 & 0,702 & 21,210 & 7,915 & 92,085 \\
\hline
\end{tabular}

Fonte: WDI (2007); WEO (2007); IFS (2006). 
Tabela 5A

Àfrica do Sul (1980 a 2005)

\begin{tabular}{|c|c|c|c|c|c|c|c|c|c|c|c|c|c|c|c|}
\hline Anos & TCPIB & ТСРОР & TAM & INF & TC & TCREF & $X$ & TCX & TRADE & $\mathrm{TJ}$ & TXI & IDE & DIVX & DIVC & DIVL \\
\hline 1980 & 6,600 & 2,330 & 0,165 & 14,200 & 0,779 & 161,759 & 35,380 & $-0,002$ & 62,729 & $-12,340$ & 25,895 & $-0,013$ & & & \\
\hline 1981 & 5,400 & 2,431 & 0,150 & 15,700 & 0,878 & 170,207 & 28,355 & $-4,871$ & 58,719 & 3,705 & 27,455 & 0,075 & & & \\
\hline 1982 & $-0,400$ & 2,507 & 0,123 & 14,400 & 1,086 & 161,278 & 26,455 & $-0,738$ & 53,324 & 4,737 & 27,496 & 0,412 & & & \\
\hline 1983 & $-1,800$ & 2,563 & 0,113 & 12,600 & 1,114 & 177,607 & 24,728 & $-2,604$ & 45,731 & 0,084 & 26,048 & 0,082 & & & \\
\hline 1984 & 5,100 & 2,595 & 0,084 & 11,200 & 1,475 & 156,664 & 25,474 & 4,107 & 49,131 & 9,697 & 23,980 & 0,493 & & & \\
\hline 1985 & $-1,200$ & 2,597 & 0,053 & 16,200 & 2,229 & 118,958 & 31,415 & 8,923 & 53,984 & 4,023 & 22,805 & $-0,675$ & & & \\
\hline 1986 & 0,000 & 2,565 & 0,050 & 18,800 & 2,285 & 109,805 & 30,571 & $-3,791$ & 52,339 & $-2,331$ & 19,646 & $-0,064$ & & & \\
\hline 1987 & 2,100 & 2,496 & 0,055 & 16,200 & 2,036 & 123,928 & 30,264 & $-1,833$ & 50,611 & $-1,745$ & 17,846 & $-0,184$ & & & \\
\hline 1988 & 4,200 & 2,387 & 0,049 & 12,900 & 2,273 & 117,043 & 29,098 & 9,811 & 51,708 & 0,130 & 19,417 & 0,138 & & & \\
\hline 1989 & 2,400 & 2,234 & 0,042 & 14,500 & 2,623 & 117,509 & 26,695 & 5,378 & 48,081 & 2,196 & 20,207 & $-0,161$ & & & \\
\hline 1990 & $-0,300$ & 2,036 & 0,042 & 14,300 & 2,587 & 122,619 & 24,237 & 1,722 & 42,999 & 4,742 & 19,145 & $-0,068$ & & & \\
\hline 1991 & $-1,000$ & 2,061 & 0,039 & 15,600 & 2,761 & 129,902 & 21,750 & $-0,057$ & 39,227 & 3,963 & 17,156 & 0,211 & & & \\
\hline 1992 & $-2,100$ & 2,087 & 0,036 & 13,700 & 2,852 & 134,203 & 21,343 & 2,533 & 38,645 & 3,783 & 15,650 & 0,003 & & & \\
\hline 1993 & 1,200 & 2,112 & 0,031 & 9,900 & 3,268 & 131,698 & 22,478 & 4,817 & 40,294 & 2,715 & 14,690 & 0,009 & & & \\
\hline 1994 & 3,200 & 2,137 & 0,028 & 8,800 & 3,551 & 126,065 & 22,103 & 4,339 & 41,962 & 5,465 & 15,151 & 0,276 & 9,368 & 24,986 & 75,014 \\
\hline 1995 & 3,100 & 2,162 & 0,028 & 8,700 & 3,627 & 122,535 & 22,772 & 10,291 & 44,866 & 6,935 & 15,881 & 0,826 & 9,541 & 27,219 & 72,781 \\
\hline 1996 & 4,300 & 2,225 & 0,023 & 7,300 & 4,299 & 112,502 & 24,729 & 9,308 & 47,925 & 10,576 & 16,285 & 0,568 & 11,584 & 29,618 & 70,382 \\
\hline 1997 & 2,600 & 2,288 & 0,021 & 8,600 & 4,608 & 118,650 & 24,596 & 5,621 & 48,033 & 11,002 & 16,511 & 2,561 & 17,233 & 28,788 & 71,212 \\
\hline 1998 & 0,500 & 2,351 & 0,017 & 6,900 & 5,528 & 109,762 & 25,653 & 4,634 & 50,163 & 13,073 & 17,094 & 0,410 & 12,166 & 31,728 & 68,272 \\
\hline 1999 & 2,400 & 2,414 & 0,015 & 5,200 & 6,109 & 103,992 & 25,335 & 1,261 & 48,075 & 10,205 & 15,455 & 1,129 & 12,071 & 30,435 & 69,565 \\
\hline 2000 & 4,200 & 2,477 & 0,014 & 5,400 & 6,940 & 99,998 & 27,871 & 8,314 & 52,786 & 5,230 & 15,144 & 0,729 & 9,773 & 24,181 & 75,819 \\
\hline 2001 & 2,700 & 1,830 & 0,011 & 5,700 & 8,609 & 87,655 & 29,959 & 1,763 & 56,030 & 5,669 & 15,051 & 6,136 & 11,402 & 21,764 & 78,236 \\
\hline 2002 & 3,700 & 1,138 & 0,009 & 9,200 & 10,541 & 73,890 & 32,709 & 0,534 & 61,221 & 4,744 & 15,024 & 0,663 & 12,147 & 19,006 & 80,994 \\
\hline 2003 & 3,100 & 1,138 & 0,013 & 5,800 & 7,565 & 97,340 & 27,907 & 0,272 & 51,091 & 10,068 & 15,823 & 0,471 & 8,714 & 14,761 & 85,239 \\
\hline 2004 & 4,800 & 1,138 & 0,015 & 1,400 & 6,460 & 107,608 & 26,568 & 2,488 & 53,849 & 5,397 & 16,249 & 0,327 & 6,322 & 12,928 & 87,072 \\
\hline 2005 & 5,100 & 1,138 & 0,016 & 3,400 & 6,359 & 108,467 & 27,095 & 6,653 & 55,654 & 5,611 & 17,163 & 2,612 & 6,881 & 13,661 & 86,339 \\
\hline $\begin{array}{l}\text { Média } 1980 \\
\text { a } 1992\end{array}$ & 1,462 & 2,376 & 0,077 & 14,638 & 1,921 & 138,575 & 27,367 & 1,429 & 49,787 & 1,588 & 21,750 & 0,019 & & & \\
\hline $\begin{array}{l}\text { Média } 1993 \\
\text { a } 2005\end{array}$ & 3,146 & 1,888 & 0,019 & 6,638 & 5,959 & 107,705 & 26,136 & 4,638 & 50,150 & 7,438 & 15,809 & 1,286 & 10,600 & 23,256 & 76,744 \\
\hline
\end{tabular}


Tabela 6A

Rússia (1993 a 2005)

\begin{tabular}{|c|c|c|c|c|c|c|c|c|c|c|c|c|c|c|c|}
\hline Anos & TCPIB & ТСРОР & TAM & INF & $\mathrm{TC}$ & TCREF & $X$ & TCX & TRADE & $\mathrm{TJ}$ & TXI & IDE & DIVX & DIVC & DIVL \\
\hline 1993 & $-8,700$ & $-0,114$ & 2,369 & 874,600 & 0,992 & 98,745 & 38,205 & 2,113 & 68,698 & 78,455 & 20,389 & 0,278 & 4,135 & 11,435 & 88,565 \\
\hline 1994 & $-12,700$ & $-0,124$ & ,900 & 307,600 & 2,191 & 100,078 & 27,758 & 12,571 & 50,954 & 75,244 & 21,811 & 0,175 &, 375 & 2,299 & 87,701 \\
\hline 1995 & $-4,100$ & $-0,132$ & 0,405 & 197,500 & 4,559 & 113,058 & 29,289 & 11,538 & 55,184 & 72,255 & 21,078 & 0,522 & 6,331 & 10,488 & 89,512 \\
\hline 1996 & $-3,600$ & $-0,272$ & 0,335 & 47,700 & 5,121 & 139,740 & 26,073 & 3,700 & 47,923 & 69,276 & 20,002 & 0,658 & 6,817 & 11,138 & 88,862 \\
\hline 1997 & 1,400 & $-0,295$ & 0,288 & 14,800 & 5,785 & 149,289 & 24,730 & $-0,500$ & 47,257 & 14,760 & 18,292 & 1,201 & 6,676 & 5,602 & 94,398 \\
\hline 1998 & $-5,300$ & $-0,275$ & 0,156 & 27,700 & 9,705 & 131,899 & 31,221 & 1,900 & 55,773 & 19,616 & 16,151 & 1,019 & 11,958 & 16,162 & 83,838 \\
\hline 1999 & 6,400 & & & & 24,620 & & & & & & & & & 791 & 82,209 \\
\hline 2000 & 10,000 & $-0,004$ & 0,058 & 20,800 & 28,129 & 100,002 & 44,061 & 9,500 & 68,094 & $-9,633$ & 16,864 & 1,045 & 9,908 & 13,096 & 86,904 \\
\hline 2001 & 5,100 & $-0,242$ & 0,058 & 21,500 & 29,169 & 120,247 & 36,893 & 4,216 & 61,111 & 1,218 & 18,888 & 0,896 & 14,333 & 15,746 & 84,254 \\
\hline 2002 & 4,700 & & & & & & & & & & & 1,002 & & 12,867 & 87,133 \\
\hline 2003 & & & 0,060 & & 30,692 & 127,308 & 35,157 & & 58,972 & $-0,818$ & 18,366 & 1,844 & 11,709 & 18,627 & 81,373 \\
\hline 2004 & 7,200 & $-0,520$ & 0,066 & 10,900 & 28,814 & 137,276 & 34,530 & 11,800 & 56,773 & $-6,834$ & 18,310 & 2,623 & 9,739 & 12,211 & 87,789 \\
\hline 2005 & 6,400 & & 0,069 & 12,700 & 28,284 & 149,246 & 35,133 & 6,300 & 56,688 & $-7,488$ & 18,178 & 1,984 & 14,632 & 8,411 & 91,589 \\
\hline $\begin{array}{l}\text { Média } 1993 \\
\text { a } 2005\end{array}$ & 1,085 & $-0,294$ & 0,376 & 127,000 & 17,647 & 121,621 & 33,960 & 7,469 & 58,190 & 22,091 & 18,509 & 1,149 & 9,651 & 12,759 & 87,241 \\
\hline
\end{tabular}

Fonte: WDI (2007); WEO (2007); IFS (2006). 